\title{
How Syndicate Short Sales Affect the Informational Efficiency of IPO Prices and Underpricing
}

\author{
Björn Bartling and Andreas Park*
}

\begin{abstract}
When a company goes public, it is standard practice that the underwriting syndicate allocates more shares than are issued. The underwriter thus holds a short position that it commonly fills by aftermarket trading when market prices fall or, when prices rise, by executing the so-called overallotment option. This option is a standard feature of initial public offering (IPO) arrangements that allows the underwriter to purchase more shares from the issuer at the original offer price. We propose a theoretical model to study the implications of this combination of short position and overallotment option on the pricing of the IPO. Maximizing the sum of both the profits from their share of the offer revenue and the potential profits from aftermarket trading, we show that underwriters strategically distort the offer price. This results either in exacerbated underpricing when favorably informed underwriters lower prices to secure a signaling benefit, or in informationally inefficient offer prices when underwriters pool in offer prices irrespective of their information.
\end{abstract}

\section{Introduction}

Price stabilization in the aftermarket of initial public offerings (IPOs) has been legal practice in the United States since the Securities Act of 1934 and is typically performed by the underwriter that organizes the IPO on behalf of the newly issued company. ${ }^{1}$ The official purpose of stabilization as stated by the Securities and Exchange Commission (SEC) is as follows: "Although stabilization is a priceinfluencing activity intended to induce others to purchase the offered security,

\footnotetext{
*Bartling, bartling@iew.uzh.ch, Institute for Empirical Research in Economics, University of Zurich, Blümlisalpstrasse 10, CH-8006 Zürich, Switzerland; Park, andreas.park@utoronto.ca, Department of Economics, University of Toronto, 150 St. George Street (Max Gluskin House), Toronto, ON M5S 3G7, Canada. Bartling thanks the European Commission's Marie Curie Fellowship Programme (Grant No. HPMT-CT-2000-00056) for financial support, and Cambridge University and Wolfson College Cambridge for their hospitality while part of this research was carried out. Park gratefully acknowledges the financial support of the Economic and Social Research Council (Grant No. R00429934339), the Royal Economic Society, and the Montague Burton Trust Fund. Special thanks go to Carolyn Pitchik and Rob McMillan for extensive discussions and Hendrik Bessembinder (the editor) and William Wilhelm (the referee) for detailed comments.

${ }^{1}$ It is also legal in the European Union based on Commission Regulation (EC) 2273/2003, which closely resembles the SEC regulations.
} 
when appropriately regulated, it is an effective mechanism for fostering the orderly distribution of securities and promotes the interests of shareholders, underwriters, and issuers." 2 While the regulator-backed aftermarket trading activities by underwriters are intended to stabilize the post-offer market price, their existence can also have undesired effects on IPO pricing. These adverse effects are the focus of this paper.

Current regulations allow underwriting investment banks (henceforth "banks") to pursue three types of aftermarket activity: First, visibly labeled stabilizing bids (though rarely observed) can be posted at or below the offer price during the distribution period of the securities. Second, penalty bids can be used to penalize customers who immediately resell ("flip") their securities in the aftermarket. ${ }^{3}$ The key feature that we focus on here is the third activity, by which banks establish a short position_-the "overallotment facility" — by selling securities in excess of the preannounced amount at the offering. Aftermarket short covering refers to the practice of filling this position in the aftermarket. Alternatively, the bank can fill the short position by exercising the overallotment option, the "greenshoe" - a call option that underwriters hold to obtain typically an additional $15 \%$ of the originally issued amount of securities from the issuer at the offer price. ${ }^{4}$

The important observation for this paper is that by combining the overallotment facility with the overallotment option, the bank can earn a risk-free profit: If the market price exceeds the offer price, covering the short position in the market would be expensive, but this loss can be avoided by drawing the overallotment option (the bank will earn extra proceeds). In fact, in the bulk of offerings, the initial short position is perfectly hedged by this option so that increasing prices are not a risk for the bank. If the price drops, the bank provides liquidity through open market purchases. In doing so, it does not accumulate inventory but covers its short positions at a price below the offer price. The difference between the market price and the offer price (minus the gross spread) is the aforementioned risk-free profit. Indeed, case studies in Jenkinson and Ljungqvist (2001) and Boehmer and Fishe (2004) document that banks can earn substantial short-covering profits. ${ }^{5}$

The purpose of this paper is to develop a model of the going-public procedure in which we can study the impact of short-covering profits on the choice of the offer price. We model a situation in which both the bank and investors

\footnotetext{
${ }^{2}$ Regulation M, Release No. 34-38067, SEC (1997), p. 81.

${ }^{3}$ See Fishe (2002) for a detailed account of penalty bid mechanisms for flippers.

${ }^{4}$ See http://www.sec.gov/divisions/corpfin/guidance/ci111400ex regs-k_sss.htm for a synopsis of the SEC rules on "syndicate short sales."

${ }^{5}$ See also Aggarwal (2000) and Ellis, Michaely, and O'Hara (2000) for cross-sectional analyses. For a further elaboration, see Fishe (2002), Sec. IV.D. More recently, Griffin, Harris, and Topaloglu (2007) provide additional evidence for underwriter aftermarket trading activities in NASDAQ IPOs. They show that lead underwriters' clients are net buyers in the aftermarket and that quid pro quo arrangements allow bookrunners to substitute client purchases for direct aftermarket support. A recent paper by SEC staff, Edwards and Hanley (2010), indicates that a substantial number of "failures to deliver" are connected to short sales. The authors of this study indicate that these failures to deliver are connected to the short-selling activities of the underwriter. While this is not hard evidence for strategic short covering, it indicates that underwriters delay their short covering, possibly waiting for even lower prices.
} 
hold private information (beyond mandatory disclosure requirements) about the intrinsic value of the offered security. The offering procedure is then a signaling game in which the bank moves first and sets the offer price. It chooses the offer price strategically to maximize its profits from both the gross spread of the offer revenue and trading profits in the aftermarket. Investors fully understand this process, and the bank anticipates the investors' best replies (i.e., their order decisions given the chosen offer price). Thus investors account for any potential losses that they may incur if the IPO trades below the offer price; in other words, potential losses are priced into the offer price. ${ }^{6}$

We first establish an informationally efficient benchmark in a setting without aftermarket activities. In this context, a separating equilibrium is informationally efficient, since the bank's information is fully revealed by the offer price; and a pooling equilibrium is informationally inefficient, as the bank's signal is concealed. Higher prices are preferred by all types of banks (and also by the company whose shares are being issued), but the banks wish to avoid incurring the reputation costs involved if the offer fails due to insufficient demand. The resulting single crossing property generates an informationally efficient equilibrium, unless the reputation costs are too low.

Introducing aftermarket short covering into the model leads to one of two outcomes: Either the offer price falls on average, or the separating equilibrium breaks down and an informationally inefficient pooling equilibrium prevails.

The exacerbated underpricing result may appear surprising because the higher the price, the larger both the offer revenue and the possible price drop. And larger price drops cause higher potential profits from short covering. This simple view would call for less underpricing. Yet signaling behavior is more subtle. In our model, banks can choose a price that is risk-free; at such a (low) price, all investors order, irrespective of their signal. Or they can choose a risky price; at this (high) price, only high-signal investors order. As there may not be enough of them, demand may be so low that the order must be rescinded.

In a separating equilibrium, a low-signal bank would choose a risk-free low price and a high-signal bank would choose a risky high price. This latter price is low enough so that it is not profitable for the low-signal bank to deviate and assume the risk of failure. Now suppose there is potentially an extra benefit from short covering. The key insight is that a low-signal bank considers a price drop in the aftermarket more likely (as it has less favorable information), and thus for a given price, potential profits from short covering are higher for the low-signal bank than for the high-signal bank. The high-signal bank, therefore, has to distort prices downward to maintain separation. A pooling equilibrium arises when it does not pay for the high-signal bank to maintain separation.

A comparative statics analysis reveals that an increase in the gross spread or an increase in the size of the short position that is covered by the overallotment option reduces the parameter set associated with informationally efficient prices, and underpricing is exacerbated for the informationally efficient prices. Thus empirically, markets in which overallotment options or spreads are larger should tend

\footnotetext{
${ }^{6}$ A substantial number of IPOs trade below their offer price: An example is the May 24, 2006, IPO of Vonage, which fell from its initial offer price of $\$ 17$ to $\$ 14.85$ on the first day of trading.
} 
to exhibit more withdrawn IPOs and higher market uncertainty due to lower information efficiency. Further, for markets that have underpricing on average but different levels of the spread or different sizes of the overallotment option, we predict that the market with larger spreads or larger overallotment options has more underpricing (controlling for all other parameters).

Turning to wealth effects, when combining the profits of a low- and a highsignal bank, it turns out that the price distortions lead to a redistribution of wealth in favor of the banks for most parameter configurations (Section V). Banks would thus prefer that the aftermarket price stabilization tools combined with the overallotment option are included in their contract. This is not immediately obvious, as high-signal banks have to lower the offer price and thus forego revenue. Yet even the high-signal bank may profit from aftermarket trading. The price distortions are not necessarily to the issuing company's detriment: While it loses if separation prevails because there is more underpricing, it is better off in a pooling equilibrium. $^{7}$

Two related papers also model the overallotment option: ${ }^{8}$ Zhang (2004) models this option as a marketing tool that is employed to induce increased demand for the offer. The existence of the option makes it easier to convince market participants to invest in information acquisition, and this should thus reduce underpricing. Aftermarket price uncertainty is exogenous in his model and, as in Benveniste and Spindt (1989), the offer cannot be overpriced. Zhang's (2004) results thus nicely complement ours, as they highlight the positive features of the overallotment option when price drops are impossible.

Fishe (2002) also emphasizes the value of the overallotment option, and in addition he shows that the presence of the option will reduce the offer price. This increased underpricing occurs because the bank can raise the (virtual) value of the overallotment option by lowering the strike (i.e., offer) price. The intuition behind his result and thus its interpretation are different from ours: In his paper the option avoids the costs of covering the initial short position at increased market prices. In our strategic model underpricing increases because the flip side-covering the short position in the market-is valuable. Increased underpricing thus occurs in our model because a bank with favorable information wants to signal that the price drop is unlikely to occur. Our contractual arrangement between issuer and underwriter is similar to that of Fishe (2002), who provides a nice justification for optimality of this arrangement (Sec. III.C). The focus of our study differs in that Fishe (2002) analyzes the impact of stock flipping, whereas we determine the informational content of offer prices and the welfare effects for issuers, bank, and investors.

Our paper fits more broadly into the recently emerging literature that studies the relation of IPO bookbuilding and aftermarket trading. For instance, our framework shares modeling analogies with Chen and Wilhelm (2008), who focus on the

\footnotetext{
${ }^{7}$ It is important to emphasize that everyone in our model is rational and understands the other players' strategies; consequently, no market participant is deceived or shortchanged.

${ }^{8}$ Two other theoretical papers with aftermarket stabilization are Benveniste, Busaba, and Wilhelm (1996) and Chowdhry and Nanda (1996). They assume that the stabilization techniques are costly for the bank and thus serve as bonding mechanisms between investors and banks to prevent overpricing.
} 
dynamic relation between share allocations and pricing. They also assume that informational asymmetries prevail after the bookbuilding process is completed. The issuer in their model would like to price-discriminate against investors, by first selling to high-valuation types at a high price (analogous to dynamic monopolistic pricing) and to low-valuation types later. While SEC regulations preclude nonuniform pricing, Chen and Wilhelm (2008) show that the issuer can still extract some of the possible price-discrimination rents by using the services of a financial intermediary who has long-term, repeated interactions with institutional investors. The intermediary would grant investors preferential allocations in future IPOs in return for implicitly implementing the price-discriminatory scheme in the IPO aftermarket. Their model thus sheds light on how IPO pricing and allocation interact when offer prices do not reflect all information.

The remainder of the paper is organized as follows. In Section II we introduce and discuss our model of the offering procedure without aftermarket short covering. Section III outlines necessary and sufficient conditions for the informationally efficient equilibria. Aftermarket short covering is introduced and its impact analyzed in Section IV, and the description of the redistribution of profits follows in Section V. Section VI concludes. The Appendix contains all the proofs and describes the tools used in the equilibrium analysis.

\section{The Benchmark Model without Short Covering}

\section{A. Overview of the Going-Public Process}

A firm that intends to go public first appoints an investment bank (which in turn assembles the sales syndicate). The initial agreement between the firm and the bank specifies the gross spread (usually 7\%) and typically grants a $15 \%$ overallotment option to the bank. The bank starts the due diligence process, and the firm files the registration statement with the SEC. The bank then circulates the preliminary prospectus ("red herring") and organizes a road show in which the firm and the bank meet with investors.

During the road show, the firm and the bank promote the IPO based upon the information contained in the prospectus. The prospectus also includes an initial indicative price range. Importantly, at this stage the "book" is built from bids of potential investors. Since the firm and the bank usually do not provide information beyond the information contained in the prospectus, the road show is primarily a vehicle for acquiring information from potential investors. ${ }^{9}$ Once the registration statement has SEC approval, the effective day can be set. Prior to the effective day, it is illegal to sell shares, so all offers submitted by investors during the road show are classified as nonbinding indications of interest.

After the road show, on the day prior to the issuance day, the firm and the bank agree on the definitive offer price and the exact number of shares to be sold. ${ }^{10}$ The offer price can lie outside the indicative price range and indeed sometimes

\footnotetext{
${ }^{9}$ The incentive problem of truthfully eliciting investors' information was first discussed in Benveniste and Spindt (1989) and Benveniste and Wilhelm (1990).

${ }^{10}$ If the firm and the bank cannot agree, then the IPO is canceled (see Busaba (2006)).
} 
does. The final prospectus (which contains the definitive offer price) is released at this point. The distribution of the stocks begins on the morning of the issuance day. Potential investors are notified of the final terms of the offering and are asked to confirm their indications of interest.

The going-public process in Europe can differ in various aspects. Most importantly, while it is strictly prohibited in the United States for the bank or the firm to interact with potential investors prior to registration with the SEC, this is routine in Europe. The bank derives its signal about the likely overall market reaction to the IPO from this interaction. It then sets the price range, which thus incorporates the bank's information. Typically, European IPOs are priced at the top end of the range (for a detailed account of the U.S.-European differences, see Jenkinson et al. (2006)) and rarely outside of it. When applying our analysis to a European context, the offer price should thus be understood as the point in the price span that is conventionally chosen. ${ }^{11}$

The bank's involvement may continue beyond the opening day of trading. First, the bank must decide whether to sell shares in excess of the original amount offered. Next, if the bank does oversell, it must cover this short position eventually either by exercising the overallotment option or by short covering in the aftermarket. In the course of these aftermarket activities, the bank might also use stabilizing or penalty bids. The final stage of an IPO begins with the end of the "quiet period," when the bank and other research analysts are allowed to comment on the valuation of the new stock.

\section{B. The Details of the Formal Model}

Staging. Our model has the following structure: The bank and the investors each receive a signal about the issuing firm, then the bank sets a price and investors decide whether or not to buy. If a sufficient number of investors buy, the issue is listed; otherwise it is withdrawn. If listed, then (after-)market prices react and aggregate all available information; any short position that the bank may have established is covered either in the market or through the overallotment option. ${ }^{12}$ This process is illustrated in Figure 1. At the end of this section, we will outline in detail how this model maps into the above, standard going-public setting.

The Security. The security on offer can take one of two equally likely values $V$; for simplicity, $V \in\{0,1\}$.

The Investors. There are $N$ identical, risk-neutral investors who can place unit orders of the security. Each investor receives a costless, private, conditionally

\footnotetext{
${ }^{11}$ Jenkinson et al. (2006) report that, for instance, $72 \%$ of German IPOs are priced at the top end of the range. Taking these conventions as given, one should note that in many respects, European IPO selling mechanisms are similar to fixed price offerings even though they are formally bookbuilding mechanisms. Partly this may be due to the fact that until the mid-1990s, European IPOs were mostly sold in fixed price offerings, as reported in Jenkinson et al. (2006). Even today, many French and almost all U.K. IPOs (see Ellul and Pagano (2006)) are sold in fixed price offerings.

${ }^{12}$ We will first establish a benchmark case without the overallotment option and without aftermarket activities and later extend the analysis to the full specification.
} 
FIGURE 1

The Timing of the Game

\begin{tabular}{|c|c|c|c|}
\hline$t=1$ & $t=2$ & $t=3$ & $t=4$ \\
\hline $\begin{array}{l}\text { The bank and } \\
\text { the investors } \\
\text { each receive a } \\
\text { signal about } \\
\text { the issuing } \\
\text { firm. }\end{array}$ & $\begin{array}{l}\text { The bank sets } \\
\text { the offer price. } \\
\text { Investors } \\
\text { decide whether } \\
\text { or not to buy. }\end{array}$ & $\begin{array}{l}\text { Shares (plus } \\
\text { short position) } \\
\text { are floated or } \\
\text { the offer is } \\
\text { with drawn. }\end{array}$ & $\begin{array}{l}\text { Aftermarket } \\
\text { trading begins. } \\
\text { The short } \\
\text { position is } \\
\text { covered in the } \\
\text { market or } \\
\text { through the } \\
\text { overallotment } \\
\text { option. }\end{array}$ \\
\hline
\end{tabular}

independent and identically distributed (i.i.d.) signal $s_{i} \in\{0,1\}$ about the value of the security. This information is noisy (i.e., $\operatorname{Pr}\left(s_{i}=v \mid V=v\right)=q_{i}$ with $q_{i} \in(1 / 2,1)$ ). If he receives a share, the investor's payoff is the market price minus the offer price, otherwise his payoff is 0. An investor's type is his signal, thus a "highsignal investor" has $s_{i}=1$, and a "low-signal investor" has $s_{i}=0$. Since the prior on the liquidation values is uniform, the signal quality $q_{i}$ coincides with the signal recipient's posterior probability assessment that the value is $V=1$.

The Issuer. We assume the issuer to be nonstrategic. He holds no private information about the value of the security and signs a standardized contract with an investment bank that specifies the amount of securities $S<N$ to be sold and that delegates the pricing decision. It also specifies the gross spread $\beta$ of the offer revenue that remains as remuneration at the bank; this way, the incentives of bank and issuer are aligned, as both would like a high revenue. The issuer's payoff is thus fraction $(1-\beta)$ of the offer revenue if the offer is floated, otherwise it is 0 .

The Bank. The risk-neutral bank receives a private signal $s_{b} \in\{0,1\}$ about the value of the security. ${ }^{13}$ This signal is noisy and conditionally independent from investors' signals and has quality $q_{b}$, where $\operatorname{Pr}\left(s_{b}=v \mid V=v\right)=q_{b}$. If $s_{b}=1$, we refer to the bank as a "high-signal bank," and if $s_{b}=0$, it is a "low-signal bank." The bank receives the signal after the contract has been signed and then announces the offer price $p$. If the offer is withdrawn, the bank's reputation is damaged and it thus incurs cost $C .{ }^{14}$ Costs that the offering procedure itself may cause are normalized to 0 . Thus, if the offer is successful, the bank's payoff is $\beta \mathrm{pS}$; if it is withdrawn, its payoff is $-C$.

The costs of a failing IPO are external to our formulation and can be thought of as capturing the opportunity costs from lost market share when associated with an unsuccessful IPO. (Withdrawals are a common phenomenon, as described, for instance in Busaba (2006) or Dunbar and Foerster (2008).) The bank's signal can be understood as its assessments of the overall market sentiment, and it is a disreputable indication of the bank's judgment to get it wrong. Indeed, there

\footnotetext{
${ }^{13}$ As argued earlier, one can also think about this as a signal about market demand. These two are correlated, but analytically it is simpler to handle a signal about the fundamental.

${ }^{14}$ The model could be extended to allow the bank to buy up unsold securities. Costs then result from expensively bought inventory positions and not from failure. Thus $C$ would be "smoothed." This would not alter our qualitative results but would complicate the analysis considerably.
} 
is evidence (Dunbar (2000)) of losses in market share subsequent to withdrawn IPOs. Moreover, companies such as Brendan Wood International make a living rating investment bank services based on issuers' satisfaction reports.

So why does the market (as a collection of all investors) not punish overpricing? In our framework the answer is simple: Investors will receive sufficient compensation for the risk of overpricing through the offer price because, as we show below, the offer is on average underpriced—so these costs are implicitly built-in.

The Offer. A fixed number of $\mathrm{S}$ securities are offered at a fixed price $\mathrm{p}$. If the demand $d$ is insufficient, $d<\mathrm{S}$, the offer fails, is thus withdrawn, and the security does not get listed. If $d \geq \mathrm{S}$, the offer is successful. If it is oversubscribed, the share allocation is prorated. After the distribution, demand $d$ is revealed to the public, the security gets listed, and market trading starts at market price $\mathrm{p}^{m}$.

\section{Two Technical Assumptions to Simplify the Analysis}

We make two simplifying assumptions that later allow us to find approximate closed-form solutions for the probability of a successful IPO and for offer prices. Define $\bar{N}\left(q_{i}\right):=64 q_{i}\left(1-q_{i}\right) /\left(2 q_{i}-1\right)^{2}$.

Assumption 1. $\mathrm{S}=\left(1-q_{i}\right) N$.

Assumption 2. The number of investors $N$ is larger than $\bar{N}\left(q_{i}\right)$.

The first assumption simplifies computations. The results of the paper will continue to hold qualitatively for any $\mathrm{S}<N / 2$, but the assumption allows us to derive approximate closed-form solutions for success probabilities and prices. The second assumption simplifies the analysis of the bank's and the investors' conditional distribution over favorable signals. The use of both will become clear when we perform the equilibrium analysis.

\section{Discussion of Our Model and Its Relation to the Institutional Conventions}

While our model abstracts from a number of institutional details of the goingpublic process, it captures the relevant informational stages: We assume that after perusing the initial prospectus, investors believe that a share of the firm has either a high or a low value, each equally likely. The IPO process in our model begins with the distribution of the preliminary prospectus, which includes the indicative price range.

The bank does not yet hold private information, so that the indicative range has no signaling value.

At this point, the bank and the issuer embark on the road show. Since the road show is primarily a tool to elicit potential investors' valuations of the security on offer, it is the bank (the "bookrunner") that learns during this process. In our model, the information that the bank acquires during the bookbuilding phase is summarized in its signal $s_{b}$. 
At the end of the bookbuilding process (i.e., after it receives its signal) the bank sets the final offer price. In our model, each investor holds private information at this point in time; this is captured by the signals $s_{i}$. This information is meant to capture the portion of investors' private information that was not revealed during the road show. ${ }^{15}$ Faced with the definitive price, each investor decides whether to uphold his indication of interest and buy the security or whether to rescind his interest (we interpret $N$ as the number of investors that indicated their interest in the offering). ${ }^{16}$

Under European conventions, the informational stages are slightly different. Since the bank solicits information from investors before the official bookbuilding starts, the bank already has information about the likely market reaction when it sets the indicative price range. For this reason, when applying our model to the European context, the range carries the informational content that only the definite offer price has under American conventions. In Europe this price range is commonly perceived as binding, and usually the definite offer price is set at the top end of this range. It is thus reasonable to model this range as a single price (which in equilibrium will be the offer price that our model yields). Investors then submit their orders based on this price (range) and their private information. Thus, when applied to the right informational stages that are outcomes of the institutional conventions, our model is general enough to span both the European and the North American setting.

\section{Offer Prices without Short Covering}

\section{A. Signaling Value of the Offer Price}

An investor bases his decision on his private information and on the information that the investment bank may reveal about its own signal through the offer price. Denote by $\mu(\mathrm{p})$ the price information and write $\mu(\mathrm{p})=1$ if the price reflects that the bank's signal is $s_{b}=1, \mu(\mathrm{p})=0$ if the price reflects that $s_{b}=0$, and $\mu(\mathrm{p})=1 / 2$ to indicate that the price is uninformative. We restrict the analysis to pure strategies. These three are thus the only relevant cases in equilibrium. ${ }^{17}$

\section{B. The Aftermarket Price}

The market price is determined by the aggregate number of favorable investor signals. In our model, this number is always revealed, either directly

\footnotetext{
${ }^{15}$ Alternatively, as in Chen and Wilhelm (2008), there could be new information that arrives after bookbuilding is complete.

${ }^{16}$ Even though indications of interest are legally nonbinding, it seems plausible that rescinding implies costs; for instance, the bank could exclude renegers from some or all its future offerings. To keep our analysis parsimonious, we abstract from such costs in our model. In supplementary material that is available on the authors' Web sites, we present a further rigorous argument that explicitly allows such costs, and we show that they will not affect the equilibrium outcome. In a nutshell, rescinding costs can be modeled as foregone future revenue. Thus, while rescinding is costly now, it is also costly in the future, implying that rescinding costs lower total payoffs. The supplementary material then shows that in such a closed system, rescinding costs will not affect the bank's decision.

${ }^{17}$ In the literature, various papers employ signaling models in IPOs; for instance, Leland and Pyle (1977) use the number of shares issued.
} 
through IPO demand or immediately after the float through trading activities. Thus, write $\mathrm{p}^{m}(d)$ for the market price as a function of $d \in\{0, \ldots, N\}$, the number of high-signal investors. Appendix A fleshes out this argument and provides an extensive treatment of price formation.

\section{Investors' Decisions and Expected Payoffs}

We admit only symmetric, pure strategies. Thus, all investors with the same signal take identical decisions. These can then be aggregated so that only three cases need to be considered: $\mathbb{B}:=\left\{B_{0,1}, B_{1}, B_{\emptyset}\right\}$, with $B_{0,1}$ denoting that all investors buy; $B_{1}$, denoting that only high-signal investors subscribe; and $B_{\emptyset}$, meaning that no investor buys.

When deciding whether or not to order a share, an investor has to account for the probability of actually obtaining a share. There are three cases to consider. First, when all investors buy, market demand is $N$ and the probability of receiving the security is $\mathrm{S} / N$. Second, suppose investor $j$ orders and $d-1$ other investors also order but overall demand is weak, $d<\mathrm{S}$. Then the IPO fails, and the investors who ordered get shares with probability 0 . Third, suppose investor $j$ and $d-1$ other investors order and $d \geq \mathrm{S}$. Then the probability that $j$ assigns to receiving the security is $\mathrm{S} / d$.

Investors order whenever their expected profit is nonnegative. After observing the offer price, an investor's information set contains both his signal $s_{i}$ and the information inferred from the offer price $\mu(\mathrm{p})$. Since signals are conditionally i.i.d., for every value $V$, there is a different distribution over the number of favorable signals $\left(s_{i}=1\right)$ among the other $N-1$ investors, which we denote $f(d-1 \mid V)$. Investor $j$ who receives signal $s_{i}$ and derives information $\mu(\mathrm{p})$ from the price assigns the following posterior distribution to the event that there are $d-1$ favorable signals among the other $N-1$ investors:

$$
\begin{aligned}
g\left(d-1 \mid s_{i}, \mu(\mathrm{p})\right):= & \operatorname{Pr}\left(V=s_{i} \mid s_{i}, \mu(\mathrm{p})\right) \cdot f\left(d-1 \mid V=s_{i}\right) \\
& +\operatorname{Pr}\left(V \neq s_{i} \mid s_{i}, \mu(\mathrm{p})\right) \cdot f\left(d-1 \mid V \neq s_{i}\right) .
\end{aligned}
$$

Assume for now that all investors with the favorable signal (and only these) order the security, case $B_{1}$. Then for a high-signal investor, at price $\mathrm{p}$ his rationalexpectation payoff from ordering has to be nonnegative,

$$
\sum_{d=\mathrm{S}}^{N} \frac{\mathrm{S}}{d} \cdot\left(\mathrm{p}^{m}(d)-\mathrm{p}\right) \cdot g\left(d-1 \mid s_{i}=1, \quad \mu(\mathrm{p})\right) \geq 0
$$

likewise for $B_{0,1}$, when we need to ensure that investors with the low signal $s_{i}=0$ want to order. In equation (2) we then replace $s_{i}=1$ with $s_{i}=0$. Also, since all buy, the summation runs from 1 to $N$, and $\mathrm{S} / d$ is replaced with $\mathrm{S} / N$.

\section{Threshold Prices}

Denote by $p_{s_{i}, \mu}$ the highest price that an investor is willing to pay if all investors with signal $\tilde{s_{i}} \geq s_{i}$ order (and only those), given signal $s_{i}$ and price information $\mu$. Thus $p_{1,1}$ is the highest separating price when only high-signal investors 
order $\left(B_{1}\right), p_{1,1 / 2}$ the highest pooling price when only high-signal investors order $\left(B_{1}\right), p_{0,1 / 2}$ the highest pooling price at which all investors buy $\left(B_{0,1}\right)$, and $p_{0,0}$ the highest separating price at which all investors buy $\left(B_{0,1}\right)$. At all these prices, investors are aware that the security price may drop in the aftermarket and that they may not get the security. The threshold prices are formally derived in Appendix C.

\section{E. The Investment Bank's Expected Payoff}

First consider case $B_{1}$. Variable $d$ denotes the number of buys (i.e., the number of high-signal investors). If the true value is $V=1$, the cumulative probability of a successful IPO is given by

$$
\operatorname{Pr}\left(d \geq \mathrm{S} \mid B_{1}\right)=\sum_{d=\mathrm{S}}^{N}\left(\begin{array}{l}
N \\
d
\end{array}\right) q_{i}^{d}\left(1-q_{i}\right)^{N-d},
$$

analogously for $V=0$. A bank with signal $s_{b}$ assigns probability $\alpha_{s_{b}}(\mathrm{~S})$ to the event that at least $\mathrm{S}$ investors have the favorable signal. Since the investment bank receives its signal with quality $q_{b}$, for $s_{b}=1$,

$$
\begin{aligned}
\alpha_{1}(\mathrm{~S})= & q_{b} \cdot \sum_{d=\mathrm{S}}^{N}\left(\begin{array}{l}
N \\
d
\end{array}\right) q_{i}^{d}\left(1-q_{i}\right)^{N-d} \\
& +\left(1-q_{b}\right) \cdot \sum_{d=\mathrm{S}}^{N}\left(\begin{array}{l}
N \\
d
\end{array}\right)\left(1-q_{i}\right)^{d} q_{i}^{N-d} .
\end{aligned}
$$

Here $\alpha_{0}(\mathrm{~S})$ is defined analogously. If the bank charges a price at which only highsignal investors buy, its expected profit is

$$
\Pi\left(\mathrm{p} \mid s_{b}, B_{1}\right)=\alpha_{s_{b}}(\mathrm{~S}) \cdot \beta \mathrm{pS}-\left(1-\alpha_{s_{b}}(\mathrm{~S})\right) \cdot C .
$$

When all investors buy, the IPO never fails and bank profits are thus $\Pi\left(\mathrm{p} \mid B_{0,1}\right)=$ $\beta \mathrm{pS}$. Of course, if the price is set so high that no investor buys, a loss of $C$ results with certainty, $\Pi\left(\mathrm{p} \mid B_{\emptyset}\right)=-C$.

Determining $\alpha_{s_{b}}$ with Assumptions 1 and 2. The two conditional distributions over favorable signals generated by $V=0$ and $V=1$ are hump-shaped, with peaks at $N\left(1-q_{i}\right)$ and $N q_{i}$, respectively. For large $N$, these two distributions become very concentrated and do not overlap. Assumption 2 ensures this; see Figure $\mathrm{C} 1$ in Appendix $\mathrm{C}$ for an illustration. ${ }^{18}$ Moreover, for large $N$, the two binomial distributions become symmetric around their modes ${ }^{19}$ so that the probability of a

\footnotetext{
${ }^{18}$ The value $\bar{N}\left(q_{i}\right)$ in Assumption 2 is derived from DeMoivre-Laplace's Theorem.

${ }^{19} \mathrm{~A}$ binomial distribution is generally not exactly symmetric around its mode. However, if $N$ is large enough, by DeMoivre-Laplace $\left(0<q_{i} \pm 2 \sqrt{q_{i}\left(1-q_{i}\right) / N}<1\right)$ we can employ the normal distribution, thus treating the distribution as symmetric around its modes. The number of traders has to be large enough so that for $V=0$ there are almost never more than $N / 2$ traders with a favorable signal, and vice versa for $V=1$. Indeed, the normality approximation applies for relatively small values of $N$ (e.g., for $q_{i}=0.75, \bar{N}=48$ ).
} 
failed IPO has a simple structure. Since the IPO fails whenever $d<\mathrm{S}$, we can use Assumption 1 to "cut" the distribution around $N\left(1-q_{i}\right)$ in half. Then the IPO fails with half the weight of the lower hump, so that $\alpha_{0}(\mathrm{~S})=\left(2-q_{b}\right) / 2$ and $\alpha_{1}(\mathrm{~S})=\left(1+q_{b}\right) / 2$. In what follows, we will omit $\mathrm{S}$ from $\alpha_{s_{b}}$.

\section{F. Conditions for Informationally Efficient Prices}

We now identify the conditions under which a profit-maximizing investment bank will reveal its information through the offer price. A separating equilibrium is defined as informationally efficient, since investors can derive the bank's signal from the offer price. In a pooling equilibrium information is shaded and thus it is informationally inefficient. In this case, investors decide only on the basis of their private signals.

The equilibrium concept for this signaling game is the perfect Bayesian equilibrium (PBE). A common problem with signaling PBEs is the multiplicity of equilibria, some being supported by "unreasonable" out-of-equilibrium beliefs. The most intuitive equilibrium, however, should be the one in which the least surplus is lost through costly signaling (sometimes referred to as the "Riley" outcome). To single out this outcome, we only consider equilibria that satisfy Cho and Kreps' (1987) intuitive criterion (IC) and, if this alone does not yield a unique outcome, we select the equilibrium that is payoff dominant for the bank.

A pooling equilibrium is specified through i) an equilibrium offer price $\mathrm{p}^{*}$ from which investors infer, ii) price information $\mu=1 / 2$, and iii) investors' best replies given their private signals, $\mu$, and $\mathrm{p}^{*}$. A separating equilibrium is i) a system of prices $\left\{\mathrm{p}^{*}, \overline{\mathrm{p}}^{*}\right\}$ and price information such that ii) at $\mathrm{p}^{*}=\overline{\mathrm{p}}^{*}$, the high separation price, the price information is that the bank has the favorable signal, $\mu=1$, and at $\mathrm{p}^{*}=\underline{\mathrm{p}}^{*}$, the low separation price, the price information is that the bank has the low signal, $\mu=0$, and iii) investors' best replies given their private signals, $\mu$, and $\mathrm{p}^{*}$. In both separating and pooling equilibria, for $\mathrm{p} \notin\left\{\overline{\mathrm{p}}^{*}, \mathrm{p}^{*}\right\}$ outof-equilibrium public beliefs are chosen "appropriately." There are three kinds of signaling equilibria in our setting: the already mentioned separating equilibrium, a pooling equilibrium in which only high-signal investors buy, and a pooling equilibrium in which all investors buy. The following result is a straightforward consequence of signaling, the proof of which is in Appendix B.

Lemma 1 (The Highest Possible Low Separating Price). There exists no separating offer price $\mathrm{p}^{*}>p_{0,0}$.

In any separating equilibrium, therefore, the low price must be such that all investors buy, and the highest such separating price, given price information $\mu=0$, is $\underline{\mathrm{p}}^{*}=p_{0,0}$. In what follows we refer to $p_{0,0}$ as the low separation price.

In our context, the Riley outcome would be so that the high-type bank chooses the highest price low enough so that the low-signal bank cannot deviate from $p_{0,0}$. More generally, for any price $\mathrm{p} \in\left[p_{0,0}, p_{0,1 / 2}\right]$ in the range of potential risk-free prices (all investors are willing to buy), define $\phi_{s_{b}}(\mathrm{p})$ as the price at which the $s_{b}$ signal bank would be indifferent between charging a risky price $\phi_{s_{b}}(\mathrm{p})$ at which 
only high-signal investors buy, $B_{1}$, and a safe pooling price $\mathrm{p}$ with $B_{0,1}$ (all investors buy). Formally,

$$
\begin{aligned}
\alpha_{s_{b}} \beta \phi_{s_{b}}(\mathrm{p}) \mathrm{S}-\left(1-\alpha_{s_{b}}\right) C & =\beta \mathrm{pS} \\
\Leftrightarrow \quad \phi_{s_{b}}(\mathrm{p}) & =\frac{\mathrm{p}}{\alpha_{s_{b}}}+\frac{1-\alpha_{s_{b}}}{\alpha_{s_{b}}} \frac{C}{\beta \mathrm{S}} .
\end{aligned}
$$

In what follows, we refer to $\phi_{1}(\mathrm{p})$ as the high-signal bank's deviation price, and to $\phi_{0}(\mathrm{p})$ as the low-signal bank's deviation price. Since $\alpha_{1}>\alpha_{0}$, the low-signal bank requires a higher price as compensation for risk taking, $\phi_{0}(\mathrm{p})>\phi_{1}(\mathrm{p})$ for all $\mathrm{p} \in\left[p_{0,0}, p_{0,1 / 2}\right]$. In addition, the higher the pooling price, the higher the lowest profitable deviation price, $\partial \phi_{j}(\mathrm{p}) / \partial \mathrm{p}>0, j \in\{0,1\}$. We can now establish our first major result.

Proposition 1 (Conditions for Informationally Efficient Prices). If i) the highsignal bank's deviation price from the highest safe pooling price is not higher than the highest separating price, $\phi_{1}\left(p_{0,1 / 2}\right) \leq p_{1,1}$, and if ii) the low-signal bank's deviation price from the low separating price is not smaller than the highest risky pooling price, $\phi_{0}\left(p_{0,0}\right) \geq p_{1, \frac{1}{2}}$ then there exists a unique PBE that satisfies the "IC," which is the following separating equilibrium:

- the low-signal bank charges $\mathrm{p}^{*}=p_{0,0}$ and all investors buy;

- the high-signal bank charges $\overline{\mathrm{p}}^{*}=\min \left\{p_{1,1}, \phi_{0}\left(p_{0,0}\right)\right\}$ and only high-signal investors buy; and

- if investors observe $\mathrm{p} \neq\left\{\mathrm{p}^{*}, \overline{\mathrm{p}}^{*}\right\}$, then $\mu=0$ and all buy if $\mathrm{p} \leq p_{0,0}$, only high-signal investors buy if $p_{0,0}<\mathrm{p} \leq p_{1,0}$, and no one buys in all other cases.

The first condition, $\phi_{1}\left(p_{0,1 / 2}\right) \leq p_{1,1}$, together with the IC, is necessary and sufficient to rule out pooling equilibria in which all investors buy, irrespective of their signals. The second condition, $\phi_{0}\left(p_{0,0}\right) \geq p_{1,1 / 2}$, ensures that there is no pooling where only high-signal investors buy, $B_{1}$. Within this range, the IC itself ensures that the bank with $s_{b}=1$ always charges the highest sustainable separating price. The high separation price $\overline{\mathrm{p}}^{*}$ is the minimum of $p_{1,1}$ and $\phi_{0}\left(p_{0,0}\right)$. The bank cannot charge more than $p_{1,1}$, and it cannot credibly charge more than $\phi_{0}\left(p_{0,0}\right)$, as otherwise the low-signal bank would deviate. Finally, since $\phi_{1}\left(p_{0,0}\right)<\phi_{1}\left(p_{0,1 / 2}\right) \leq p_{1,1}$, the high-signal bank is willing to separate. The third bullet specifies the out-of-equilibrium beliefs and behavior supporting the equilibrium. Details are in Appendix B.

\section{G. Underpricing}

In the context of this model, underpricing occurs if the (first-day) market price is above the offer price.

Proposition 2 (Underpricing). In a separating equilibrium, on average, securities are underpriced.

Both types of investors only buy if their expected payoff is nonnegative. At $p_{0,0}$, the low-signal investor breaks even in expectation but the high-signal investor expects a strictly positive payoff. At $p_{1,1}$, the high-signal investor just 
breaks even and the low-signal investor abstains. Ex ante, the expected payoff is positive, hence underpricing.

This result is a natural consequence of the winner's curse type of reasoning that underlies the ordering decision of informed investors: Offers may be overpriced, and on average they require compensation to be insured against the potential payoff loss from an overpriced offering. Proposition 2 thus demonstrates that our model is in line with extant IPO models such as Rock (1986).

\section{H. An Intuitive Characterization of the Equilibrium}

Deviation prices $\phi_{s_{b}}$ are a convenient tool to describe restrictions. We will now reformulate the conditions from Proposition 1 in terms of exogenous costs $C$. This allows us to derive a simple linear characterization of the equilibrium. Consider Proposition 1's first condition, $\phi_{1}\left(p_{0,1 / 2}\right) \leq p_{1,1}$. If $C$ is so high that

$$
\phi_{1}\left(p_{0, \frac{1}{2}}\right)=\frac{p_{0, \frac{1}{2}}}{\alpha_{1}}+\frac{1-\alpha_{1}}{\alpha_{1}} \frac{C}{\beta \mathrm{S}}>p_{1,1},
$$

then, assuming the payoff-maximizing equilibrium for the bank, a separating equilibrium cannot be sustained. Even a high-signal bank then prefers to sell the security at a price where all investors buy. Consider now Proposition 1's second condition, $\phi_{0}\left(p_{0,0}\right) \geq p_{1,1 / 2}$. If $C$ is so low that

$$
\phi_{0}\left(p_{0,0}\right)=\frac{p_{0,0}}{\alpha_{0}}+\frac{1-\alpha_{0}}{\alpha_{0}} \frac{C}{\beta \mathrm{S}}<p_{1, \frac{1}{2}},
$$

then a separating equilibrium, again, cannot be sustained (by payoff dominance). In this case, even a low-signal bank is willing to choose a high, risky pooling price and the high-signal bank can thus not credibly signal its information. If $C$ is so high that $\phi_{0}\left(p_{0,0}\right)>p_{1,1}$, then for the low-signal bank it does not even pay to deviate to the highest separating price, $p_{1,1}$. This bound on $C$ is given by

$$
\hat{C}:=\frac{\alpha_{0} p_{1,1}-p_{0,0}}{1-\alpha_{0}} \beta \mathrm{S}
$$

Define, analogously, $\bar{C}$ and $\underline{C}$ such that (7) and (8) hold with equality. We get $\underline{C}<\hat{C}<\bar{C}$.

Corollary 1 (Proposition 1 in Terms of Costs). If $C \in(\underline{C}, \bar{C})$, then the unique equilibrium is the separating equilibrium from Proposition 1 . If $C \in(\underline{C}, \hat{C})$, then $\overline{\mathrm{p}}^{*}=\phi_{0}\left(p_{0,0}\right)$, and if $C \in[\hat{C}, \bar{C})$, then $\overline{\mathrm{p}}^{*}=p_{1,1}$.

It has often been argued that certifying agents, here the investment bank, must have "enough" reputation capital at stake to make certification credible. In this context, "too much" reputation can also inhibit certification (separation from a low-signal bank) if it becomes too expensive to jeopardize one's reputation at a high, risky offer price. Figure 2 illustrates threshold costs and corresponding equilibrium prices. 
FIGURE 2

Threshold Costs and Equilibrium Prices

For low costs, $C \leq \underline{C}$, if the high-signal bank wants to uphold separation it would have to set a price below the risky pooling price $p_{1}, 1 / 2$; since this is too expensive, pooling in price $p_{1}, 1 / 2$ prevails. For a medium range of costs, $C \in(\underline{C}, \bar{C})$, there will be a separating equilibrium. For the high end of this range, $C \in[\hat{C}, \bar{C})$, the high-signal bank can charge the highest separating price $\overline{\mathrm{p}}^{*}=p_{1}, 1$. For the lower end, $C \in(\underline{C}, \hat{C})$, however, the high-signal bank cannot charge the highest separation price. Instead, to prevent the low-signal bank from mimicking, it must set a lower price $\phi_{0}\left(p_{0,0}\right) \in$ $\left(p_{1}, 1 / 2, p_{1,1}\right)$. Finally, for very large withdrawal costs, $C \geq \bar{C}$, separation is too risky for the high-signal bank, so that pooling in a risk-free price $p_{0,1 / 2}$ results.

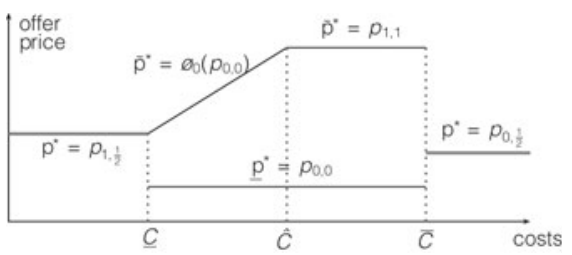

\section{The Impact of Aftermarket Short Covering}

\section{A. Overview of Short Covering and a Bank's Strategy}

Aftermarket short covering works as follows: Instead of issuing the principal volume of securities $\mathrm{S}$, the investment bank overallots $\mathrm{O}$ securities (i.e., it takes a short position of $\mathrm{O}$ shares).

Suppose first that the market price falls below the offer price. Then the bank would fill its short position in the market at this lower price. This practice is referred to as aftermarket short covering. If the market price is below the offer price (minus the gross spread), then the bank makes a trading profit.

Now suppose that the market price rises above the offer price. Covering in the market would now be costly. However, most IPO contracts grant the bank a call option (the so-called overallotment option) for a certain number of additional securities that the bank can obtain at the offer price from the issuer. If the bank has this option and if its size is also $\mathrm{O}$, then it is perfectly hedged against rising prices and it may make a profit if prices drop. We will now analyze how these potential aftermarket trading profits affect the bank's strategy.

For simplicity, we assume that the bank issues either $\mathrm{S}+\mathrm{O}$ or 0 securities; that is, if demand is below $\mathrm{S}+\mathrm{O}$ then, as in the case without short covering, the offer is withdrawn. Moreover, we assume that the overallotment of shares coincides with the size of the overallotment option. ${ }^{20}$ This merely simplifies the analysis and does not affect the qualitative results.

We will now identify two scenarios that may result from introducing aftermarket short covering. In the first, the high-signal bank sets a lower price (relative to the benchmark without short covering) to uphold separation from a low-signal bank. The second scenario arises when upholding separation becomes too expensive, in which case the high-signal bank starts to pool with the low-signal bank. The result is an informationally inefficient outcome.

\footnotetext{
${ }^{20}$ The SEC states on its Web site that "most offerings have a short position at least equal to the underwriters' overallotment option" (http://www.sec.gov/divisions/corpfin/guidance/ci111400ex_regs-k_ sss.htm).
} 
The intuition for our results is simple: With short covering, large price drops lead to large short-covering profits. Price drops occur with higher probability if the underlying state is bad, and thus low-signal banks consider a price drop to be more likely. In the benchmark separating equilibrium, a low-signal bank would not mimic a high-signal bank because it fears costs from a potential IPO failure. With aftermarket trading gains, however, some of the potential losses from a failed offering are offset by the prospect of aftermarket trading profits.

Figure 3 offers an illustration of the transfers between issuer, bank, and investors.

\section{FIGURE 3}

\section{Flows of Shares and Cash}

Figure 3 illustrates the flows of shares and cash between issuer, bank, and investors. Graph A describes transfers if short covering is not allowed. Graph B shows the transfers when short covering is allowed but does not take place because the bank exercises its option. Graph $\mathrm{C}$ documents that when short covering does take place (the market price $\mathrm{p}^{m}$ drops below the offer price $p$ ), there are additional transfers: $O$ shares are sold short to investors at the offer price $p$ and are bought back at the market price $\mathrm{p}^{m}$.

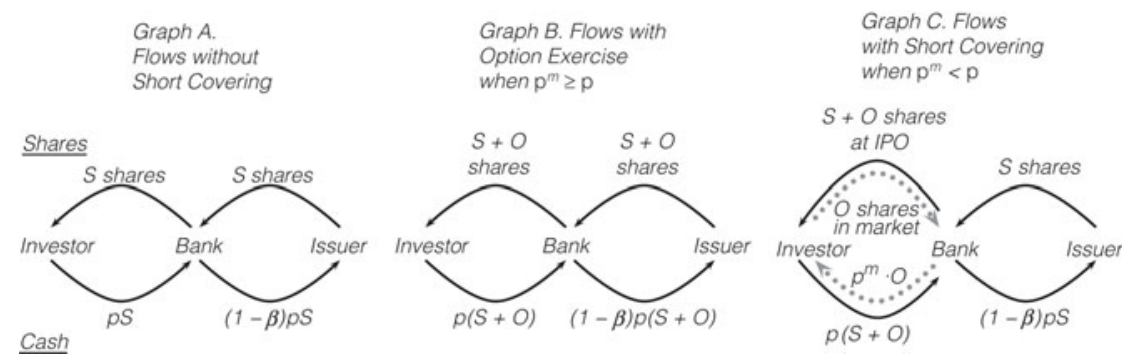

In what follows, we will denote functions, threshold values, and variables that pertain to the analysis with short covering by superscripts SC.

\section{B. Payoffs with Short Covering}

If the market price exceeds the offer price, $\mathrm{p}^{m}(d)>\mathrm{p}$, then the bank exercises the short position and keeps the gross spread $\beta$ Op for these shares. If the market price drops, $\mathrm{p}^{m}(d)<\mathrm{p}$, then the bank covers its short position in the market, earns trading profit $\mathrm{p}-\mathrm{p}^{m}(d)$, but does not obtain the spread on the $\mathrm{O}$ overallotted shares.

We now write $\Pi\left(\mathrm{p}^{*}, B, s_{b}\right)$ for the investment bank's expected profits from the offer revenue, and we use $\Pi^{\mathrm{SC}}\left(\mathrm{p}^{*}, B, s_{b}\right)$ for the trading profits. Suppose the offer price $\mathrm{p}$ is risky (i.e., only high-signal investors order). Then

(10) $\Pi^{\mathrm{SC}}\left(\mathrm{p}, B_{1}, s_{b}\right)=\sum_{d=\mathrm{S}+\mathrm{O}}^{N} \mathrm{O} \cdot \max \left\{(1-\beta) \cdot \mathrm{p}-\mathrm{p}^{m}(d), 0\right\} \cdot \operatorname{Pr}\left(d \mid s_{b}\right)$.

For a safe price (at which all investors buy) the summation runs from 0 to $N$. The bank also accounts for the foregone gross spread $\beta$ when buying back in the market. 


\section{Equilibrium Analysis}

With short covering allowed, a high separation price, $\overline{\mathrm{p}}^{*}$ has to be small enough so a low-signal bank cannot profitably deviate from the low, risk-free price, $p_{0,0}$. Thus the high-signal bank has to determine the low-signal bank's deviation price $\phi_{0}^{\mathrm{SC}}\left(p_{0,0}\right)$ so that

$$
\begin{gathered}
\Pi\left(\phi_{0}^{\mathrm{SC}}\left(p_{0,0}\right) \mid s_{b}=0, B_{1}\right)+\Pi^{\mathrm{SC}}\left(\phi_{0}^{\mathrm{SC}}\left(p_{0,0}\right) \mid s_{b}=0\right)= \\
\Pi\left(p_{0,0} \mid s_{b}=0, B_{0,1}\right)+\Pi^{\mathrm{SC}}\left(p_{0,0} \mid s_{b}=0\right) .
\end{gathered}
$$

In what follows, we make two further assumptions.

Assumption 3. Assume $\mathrm{S}+\mathrm{O}=\left(1-q_{i}\right) N$.

Assumption 4. Assume $q_{i}$ and $q_{b}$ are sufficiently informative so that $p_{1,1 / 2}>$ $2 p_{0,0}$.

Assumption 3 states that the overall amount of shares that can be issued remains constant relative to the scenario without aftermarket short covering. This normalization allows a straightforward comparison of the payoffs in both scenarios. If we keep the number of issued shares constant, then the offer revenue is only affected by changes in the price. It also allows us to continue to use the closed-form price approximations. Assumption 4 requires that the signals of the investors and the bank jointly are sufficiently informative. The assumptions allow us to avoid several case distinctions. Figure 4 in Section V has an illustration of the parametric configuration that corresponds to Assumption 4.

Lemma 2 (The Low-Signal Bank's Deviation Price Drops). For all prices $\mathrm{p} \in$ $\left[p_{0,0}, p_{0,1 / 2}\right]$, the low-signal bank's deviation price with short covering $\phi^{\mathrm{SC}}(\mathrm{p})$ is smaller than without short covering, $\phi_{0}(\mathrm{p}) \geq \phi_{0}^{\mathrm{SC}}(\mathrm{p})$.

The low-signal bank considers it more likely than the high-signal bank that the price drops, hence its potential gain from short covering is large, in particular, relative to trading profits at the low separation price. This additional incentive for the low-signal bank to mimic the high-signal banks forces the high-signal bank to reduce its offer price further compared to the scenario without short covering.

In what follows, if there is a switch from separating to pooling, we restrict attention to those situations where the new equilibrium price is the risky pooling price $p_{1,1 / 2}{ }^{21}$ We can now establish the main result. Analogously to Corollary 1 , we spell it out in terms of the costs of withdrawal.

\section{Proposition 3 (Equilibrium with Short Covering Relative to the Benchmark).}

i) There exists a lower bound $\underline{C}^{\mathrm{SC}}>\underline{C}$ such that for all costs $C \in\left[\underline{C}, \underline{C}^{\mathrm{SC}}\right)$, the only equilibrium that satisfies the IC and payoff dominance is a pooling equilibrium at the highest risky pooling price $p_{1,1 / 2}$. This price is informationally inefficient.

\footnotetext{
${ }^{21}$ Our results on informational efficiency are not affected by this restriction. To the contrary, taking pooling in a risk-free price into account would strengthen our findings. In addition, if there is a choice between the high, risky pooling price, $p_{1,1 / 2}$, and the low, safe pooling price, $p_{0,1 / 2}$, the former will always generate more ex ante revenue.
} 
ii) There exists an upper bound $\bar{C}^{\mathrm{SC}}$ such that for all costs $C \in\left[\underline{C}^{\mathrm{SC}}, \bar{C}^{\mathrm{SC}}\right]$, the unique equilibrium that satisfies the IC and payoff dominance is a separating equilibrium. For the high separating price $\overline{\mathrm{p}}^{*}$, there exists a threshold $\hat{C}^{\mathrm{SC}} \in$ $\left[\hat{C}, \bar{C}^{\mathrm{SC}}\right)$ so that

a) for costs $C \in\left[\underline{C}^{\mathrm{SC}}, \hat{C}^{\mathrm{SC}}\right)$, the high separation price is the low-signal bank's deviation price from the low separating price, $\overline{\mathrm{p}}^{*}=\phi_{0}^{\mathrm{SC}}\left(p_{0,0}\right)$, $p_{1,1 / 2}<\phi_{0}^{\mathrm{SC}}\left(p_{0,0}\right)<p_{1,1}$, and

b) for costs $C \in\left[\hat{C}^{\mathrm{SC}}, \bar{C}^{\mathrm{SC}}\right]$, the high separation price is the highest risky price $\overline{\mathrm{p}}^{*}=p_{1,1}$.

iii) On average, underpricing in the separating equilibrium is exacerbated.

The intuition for the result is as follows: i) When costs of withdrawal are low, then without short covering, the high separation price is already close to the risky pooling price. With short-covering profits, the bank would now have to lower the high separation price below the risky pooling price to uphold separation. This is payoff dominated by pooling.

In ii)b, in contrast, costs are so high that the additional short-covering benefit is too small to entice the low-signal bank into mimicking; neither the high nor the low separation price is thus affected.

Part ii)a describes the middle region of costs where separation can be upheld, but only by reducing the high separation price. Since separating prices weakly decrease, underpricing increases (part iii).

At first glance, the result that average prices are lower is surprising because, after all, the short-covering profits are expected to be larger when the offer price is higher. Agents should thus be even more inclined to set higher prices. But this casual intuition is inaccurate because the driving force in equilibrium is not the low-signal bank's aspiration to exploit these profits but the high-signal bank's defense against the low-signal bank's desires. This defense involves either lowering the risky price or surrendering to pooling and thus making offer prices less informative. $^{22}$

\section{Comparative Statics}

We can express the overallotment option $\mathrm{O}$ as a share $r$ of $\mathrm{S}, \mathrm{S}+\mathrm{O}=(1+r) \mathrm{S}$. Thus, value $r=0$ is the benchmark case without short covering. Potential policy

\footnotetext{
${ }^{22}$ The argument here focuses on the relation of lower bound threshold costs $\underline{C}$ and $\underline{C}^{\mathrm{SC}}$ and "middle" bound threshold costs $\hat{C}$ and $\hat{C}^{\mathrm{SC}}$. Since $\hat{C}^{\mathrm{SC}}$ increases relative to $\hat{C}$ (by Lemma 2 ) and since also $\underline{C}^{\mathrm{SC}}$ increases relative to $\underline{C}$, then also $\bar{C}^{\mathrm{SC}}$ should increase relative to $\bar{C}$. But this is not necessarily true- it may actually decrease. Keeping $N, \beta$, and $\mathrm{O}$ fixed, $\bar{C}$ and $\bar{C}^{\mathrm{SC}}$ are functions of the signal qualities $q_{b}$ and $q_{i}$. For low-signal qualities, $\bar{C}^{\text {SC }}$ actually decreases. For such values, the high separation price $p_{1,1}$ and the low, risk-free pooling price $p_{0,1 / 2}$ are close. Expected aftermarket profits are higher for the risk-free price, and this outweighs the lower expected pooling revenue. This strengthens our result on informational inefficiency. While $\bar{C}^{\mathrm{SC}}$ does increase relative to $\bar{C}$ for high values of $q_{b}$ and $q_{i}$, numerically these costs are far off scale in the following sense: A natural upper bound for costs $C$ is provided by the loss of all (discounted) future business. This upper bound on $C$ can actually be calculated, and it turns out that for all those combinations of $q_{i}$ and $q_{b}$ for which $\bar{C}^{\mathrm{SC}}$ increases, the value $\bar{C}$ far exceeds this "natural" upper bound. Appendix D outlines the details of this argument.
} 
variables in our model are the bank's share of the revenue, $\beta$, and the size of the overallotment option, $r$.

Proposition 4 (Comparative Statics). If the gross spread, $\beta$, or the size of the overallotment facility, $r$, increases, then $\underline{C}^{\text {SC }}$ increases so that the conditions for informational efficiency become more restrictive. Moreover, the difference $\hat{C}^{\mathrm{SC}}-\underline{C}^{\mathrm{SC}}$ increases so that average underpricing in the separating equilibrium increases.

A higher level of $\beta$ or $r$ strengthens the bank's incentive to set higher prices, so that the high-signal bank has to lower its price to defend its high separation price. When the high separation price is low, it gets too expensive to defend separation by lowering the price so that pooling in $p_{1,1 / 2}$ results; this increases $\underline{C}^{\mathrm{SC}}$. Close to $\hat{C}^{\mathrm{SC}}$, we use the smallest cost so that the highest separation price $p_{1,1}$ is employed; separation is thus upheld by employing a smaller high separation price.

The result can be illustrated with Figure 2, where an increase in $\beta$ or $r$ shifts the entire function to the right. Moreover, the slope of the increasing portion of the function becomes smaller because $\hat{C}^{\mathrm{SC}}$ increases by more than $\underline{C}^{\mathrm{SC}}$. This implies an increase of the parameter area for which there is separation in a price that is smaller than the largest high separation price, $p_{1,1}$; this means that underpricing is more than proportionally exacerbated.

Empirically, if there is more pooling, then all banks will set a high price, thus risking that they may have to withdraw the IPO. If there is average underpricing for a given cost level, then underpricing is positively related to the size of the spread and the overallotment option.

\section{Payoff Analysis}

Covering a short position in the market at a price below the offer price is unambiguously profitable. Yet it is not immediately obvious that the possibility of short covering is profitable: Compared to the setting without short covering, the high-signal bank has to lower prices to "defend" itself against the low-signal banks. This lowers the offer revenue. At the same time, the high-signal bank may also, in expectation, earn some short-covering profits. We now determine the net effect.

\section{A. Payoff Comparison for the Investment Bank}

As outlined at the beginning of Section II, the bank obtains its signal after making the initial arrangements with the issuer. So at that initial stage, would the bank prefer it if the possibility of short covering is included in the contract? To answer this question we sum the payoffs of the high- and low-signal banks and compare the payoffs with and without short covering.

In general this payoff depends on all model variables, such as costs, signal qualities, number of investors, spreads, and so on. To get a sense of the extent of the payoff shifts, we look at the most extreme drop in revenue that may occur. This drop occurs if the high-separation price drops to (almost) the high, risky pooling price. Then separation is upheld with $\overline{\mathrm{p}}^{\mathrm{SC}}=p_{1,1 / 2}$ and $\underline{\mathrm{p}}^{\mathrm{SC}}=p_{0,0}$. This scenario also involves the lowest possible short-covering profits. 
We thus combine payoffs for high- and low-signal banks to compute the difference of payoffs with and without short covering:

$$
\begin{aligned}
& \Pi\left(p_{1, \frac{1}{2}} \mid s_{b}=1, B_{1}\right)+\Pi^{\mathrm{SC}}\left(p_{1, \frac{1}{2}} \mid s_{b}=1, B_{1}\right)-\Pi\left(p_{1,1} \mid s_{b}=1, B_{1}\right) \\
& \quad+\Pi\left(p_{0,0} \mid s_{b}=0, B_{0,1}\right)+\Pi^{\mathrm{SC}}\left(p_{0,0} \mid s_{b}=0, B_{0,1}\right)-\Pi\left(p_{0,0} \mid s_{b}=0, B_{0,1}\right) .
\end{aligned}
$$

Expanding this expression, one can see that withdrawal costs cancel and that the sign of the expression will not depend on $N$. Fixing spread and overallotment option to the commonly observed value $\beta=7 \%$ and $r=15 \%$, we illustrate in Figure 4 that for a very large subset of parameter configurations $q_{i}$ and $q_{b}$, the bank gains. Moreover, the set of parameters where banks lose is "visually" exaggerated because we measure only the worst possible payoff outcome. It arises if parameters are such that $\underline{C}^{\mathrm{SC}}>\hat{C}$, which does not necessarily occur. And even if $\underline{C}^{\mathrm{SC}}>\hat{C}$, then the bank loses only for a specific subset of these costs $C$. The right panel in Figure 4 illustrates this point. Details of the computations are in Appendix E.

\title{
FIGURE 4
}

\section{Informational Efficiency and the Sign of the Bank's Net Profit}

\begin{abstract}
Graph A: For parameters in the large light gray area, banks are better off on average. In the top right area, the bank may lose. However, the graph is drawn for the scenario in which payoffs with short covering are lowest, and it is compared to a scenario when payoffs without short covering are highest. The circled area in Graph B indicates a situation where payoffs decline, and it also illustrates why the set of such parameters is potentially quite small. The bottom left area is excluded by Assumption 4. The figure is drawn for the standard empirical parameters $\beta=7 \%, \mathrm{O}=\mathrm{S} \times 15 \%$.

Graph B: The figure draws profits of the bank as a function of withdrawal costs $C$; the lower, black line is for the case without short covering, and the higher, gray lines are for the case with short covering. Profits with short covering are lowest at $\underline{C}^{S C}$, and the most extreme scenario of price drops relative to the situation without short covering combined with lowest short-covering profits occur when $\hat{C}<\underline{C}^{S C}$. The figure is drawn for this case. For the highest, dashed line, the bank gains for every value $C$; in Graph $A$, this corresponds to the light gray area. For the lower, solid gray line, there is a range of costs so that the bank loses. This corresponds to the upper right area in Graph A. As can be seen, even if parameters are such that $\hat{C}<C^{S C}$, then the bank loses only for a small subset of costs. Moreover, a scenario where $\hat{C}<C^{S C}$ holds only for a subset of parameters (which is, however, not visible from these graphs). Appendix E describes in detail how these graphs are derived.
\end{abstract}

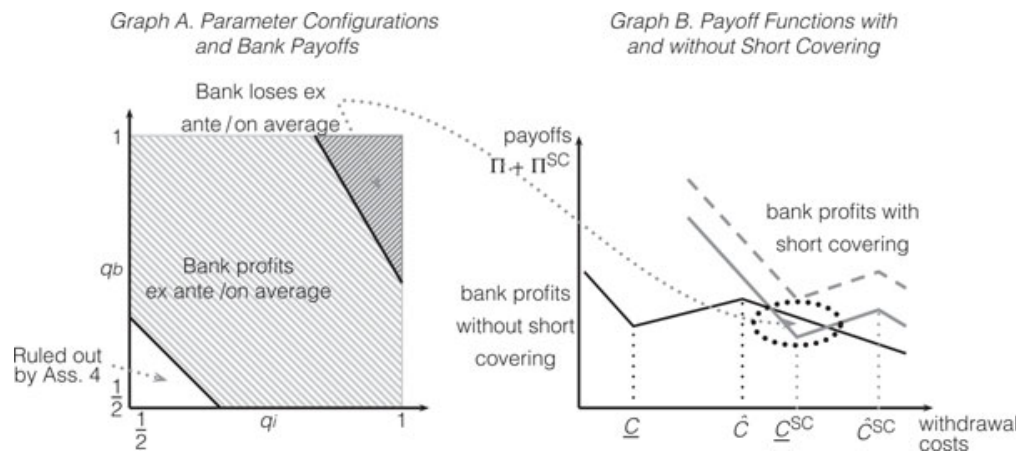

\section{B. Payoff Comparison for Issuer and Investors}

Given our model specification we can only compare the revenue that the issuer receives in settings with and without short covering. ${ }^{23}$ Suppose that with

\footnotetext{
${ }^{23}$ This is equivalent to expected profits: Profits here would be defined as the difference between revenue per share and the true value, which, by the law of large numbers (LLN), is identical to the aftermarket price.
} 
short covering, separation is maintained. If the high separation price decreases, $\overline{\mathrm{p}}^{\mathrm{SC}}<\overline{\mathrm{p}}$, then the issuer loses.

Yet if there is a switch from separation to pooling, then the issuer may actually gain. The reason is that the expected price with separation is $1 / 2 p_{0,0}+1 / 2 \alpha_{1} p_{1,1}$, whereas with pooling it is $3 / 4 p_{1,1 / 2}$. Using closed-form expressions for prices that are outlined in the Appendix and some straightforward algebra, one can see that payoffs with pooling are larger. ${ }^{24}$ In other words, the issuer prefers the bank to play a pooling equilibrium.

Investors' profits are directly opposed to the issuer's profit. Whenever the issuer gains (in expectation), investors lose and vice versa.

Even though this section is merely concerned with redistribution, it yields an interesting insight. The investment bank is nearly always better off with aftermarket short covering. The issuer never gains but often loses if separation is upheld, but the issuer wins if banks switch from separation to pooling; the effect on investors' payoffs is the opposite.

\section{Conclusion}

It is common legal practice that investment banks pursue price stabilizing activities in the aftermarket of IPOs. We propose a theoretical model that highlights the strategic impact of potentially profitable aftermarket trading on the offer price. Our analysis shows that either the offer price is rendered informationally inefficient or, on average, underpricing is exacerbated as compared to the benchmark case without aftermarket price stabilization.

On a more general level, with efficient, frictionless markets there would be no need for price stabilization. As it stands, however, price stabilization is allowed by the regulator, suggesting that the IPO aftermarket is considered to be an imperfect market. When operating and regulating in such an environment, one must ensure that posited rules do not create a whole new set of problems. Underwriter trading activities in the IPO aftermarket are usually rationalized as a means to ensure "a more orderly distribution of securities" and "a smaller aftermarket price volatility." We do not contest that these benefits exist. Before attaching payoffs to these "soft" factors, however, it is imperative to first determine "hard" payoff shifts that can be directly attributed to aftermarket short covering. To ensure that the possibility of aftermarket short covering does not reduce informational efficiency or increase underpricing, the bank could be prohibited from filling short positions at prices below $1-\beta$ times the offer price.

Of course, in the current environment, short-covering profits are possible and are thus accounted for by the banks. Eliminating short-covering profits lowers banks' total profits. All else being equal, at the margin this may cause banks to decline contracts so that some companies cannot go public unless the gross spread increases. Yet as Chen and Ritter (2000) say, "Investment bankers readily

\footnotetext{
${ }^{24}$ There is a small region of parameters, so that separation is still preferred because when short covering does take place, fewer shares are issued.
} 
admit that the IPO business is very profitable," so it seems unlikely that banks' participation constraints would be violated in most cases.

\section{Appendix A. Aftermarket Price Formation}

An efficient market price correctly aggregates the number of positive and negative signals about the value of the security. The offer demand is published after securities have been issued. If only high-signal investors buy the offer, this demand reveals the total number of good (and bad) signals. If all investors order the security, stated demand is $N$, securities are allocated at random, but the demand is uninformative. Still, high-signal investors expect the security to be worth more than low-signal investors, and thus high-signal investors without a share allotment are willing to buy it from low-signal investors with a share allotment. Without modeling the price-finding procedure explicitly, we assume that an intermediate market process reveals the number of high signals $d$. For instance, highsignal investors without a share allotment submit unit market-buy orders, and low-signal investors with a share allotment submit unit market-sell orders. All other investors abstain. Let $\tilde{d}$ be the number of buyers and $\tilde{S}$ the number of sellers. Then the number of highsignal investors is $\tilde{d}+\mathrm{S}-\tilde{S}$, and the market price $p^{m}$ will again depend on the number of favorable signals $d$. The updated expectation of $V$ thus becomes the aftermarket price, $\mathrm{p}^{m}(d)=\mathrm{E}[V \mid d, \mu]=\operatorname{Pr}(V=1 \mid d, \mu)$. Using Bayes' rule, we can express the aftermarket price as

$$
\begin{aligned}
& \mathrm{p}^{m}(d \mid \mu=1) \\
& \quad=\frac{\operatorname{Pr}(d \mid V=1) \operatorname{Pr}\left(s_{b}=1 \mid V=1\right)}{\operatorname{Pr}(d \mid V=1) \operatorname{Pr}\left(s_{b}=1 \mid V=1\right)+\operatorname{Pr}(d \mid V=0) \operatorname{Pr}\left(s_{b}=1 \mid V=0\right)} .
\end{aligned}
$$

The conditional prior distribution over signals has binomial structure, $\operatorname{Pr}(d \mid V=1)=$ $\left(\begin{array}{l}N \\ d\end{array}\right) q_{i}^{d}\left(1-q_{i}\right)^{N-d}$. Price information $\mu$ about $s_{b}$ is unambiguous in a separating equilibrium. We can therefore replace it with the conditional probability of the bank's signal being correct, $q_{b}$ or $1-q_{b}$. Then

$$
\mathrm{p}^{m}(d \mid \mu=1)=\frac{q_{b} q_{i}^{2 d-N}}{q_{b} q_{i}^{2 d-N}+\left(1-q_{b}\right)\left(1-q_{i}\right)^{2 d-N}} .
$$

\section{Appendix B. Omitted Proofs}

Proof of Lemma 1. Suppose $\mathrm{p}^{*}>p_{0,0}$. At this price, only high-signal investors buy. A high-signal bank will always set a price where at least high-signal investors buy. Hence, high-signal investors buy at both prices $\underline{\mathrm{p}}^{*}$ and $\overline{\mathrm{p}}^{*}$. A low-signal bank can now increase its payoff by setting a higher price, as $\alpha_{0}$ is not affected by this, a contradiction.

Proof of Proposition 1. First we will argue that the only separating equilibrium surviving the intuitive criterion (IC) is the one outlined in the proposition. Then we will argue that pooling cannot occur.

Step 1 (Separating). First observe that there cannot be a separating price $\overline{\mathrm{p}}^{*}$ where investors choose $B_{0,1}$ because otherwise the low-signal bank would deviate to this price. Note that no separating price with $\overline{\mathrm{p}}^{*}>\phi_{0}\left(p_{0,0}\right)$ can exist because at this price, the lowsignal bank would prefer to deviate. No price $\overline{\mathrm{p}}^{*}>p_{1,1}$ can exist, since not even highsignal investors would buy. Furthermore, $\overline{\mathrm{p}}^{*} \geq \phi_{1}\left(p_{0,0}\right)$ must be satisfied, since otherwise the high-signal bank would prefer to deviate to $p_{0,0}$. Finally, no price $\bar{p}^{*}$ below $p_{1,0}$ is reasonable because the high-signal bank would then deviate to this price. Take $\tilde{p}$, with 
$\max \left\{\phi_{1}\left(p_{0,0}\right), p_{1,0}\right\} \leq \tilde{p} \leq \min \left\{p_{1,1}, \phi_{0}\left(p_{0,0}\right)\right\}$. Note that such a $\tilde{p}$ always exists as long as $\phi_{1}\left(p_{0,0}\right) \leq p_{1,1}$ and $p_{1,0} \leq \phi_{0}\left(p_{0,0}\right)$. The conditions stated in Proposition 1 ensure this is the case because $\phi_{1}\left(p_{0,1 / 2}\right)>\phi_{1}\left(p_{0,0}\right)$ and $p_{1,1 / 2}>p_{1,0}$.

We analyze the candidate separating equilibrium

$$
\begin{aligned}
& \left\{\left(\underline{\mathrm{p}}^{*}=p_{0,0}, \mu=0, B_{0,1}\right) ;\left(\overline{\mathrm{p}}^{*}=\tilde{p}, \mu=1, B_{1}\right) ;\right. \\
& \left.\left(\mathrm{p}^{*} \notin\left\{\underline{\mathrm{p}}^{*}, \overline{\mathrm{p}}^{*}\right\}, \mu=0, B_{0,1} \text { if } \mathrm{p} \leq p_{0,0}, B_{1} \text { if } p_{0,0}<\mathrm{p} \leq p_{1,0}, B_{\emptyset} \text { else }\right)\right\} .
\end{aligned}
$$

By definition of $\phi_{0}\left(p_{0,0}\right)$, it holds that

$$
\beta p_{0,0} \mathrm{~S}=\alpha_{0} \beta \phi_{0}\left(p_{0,0}\right) \mathrm{S}-\left(1-\alpha_{0}\right) C>\alpha_{0} \beta \tilde{p} \mathrm{~S}-\left(1-\alpha_{0}\right) C,
$$

so that the low-signal bank would not deviate to $\tilde{p}$. Since $\max \left\{\phi_{1}\left(p_{0,0}\right), p_{1,0}\right\} \leq \tilde{p}$, the high-signal bank also would not deviate. Hence this is a PBE.

Now consider the application of the IC. Suppose a high separation price $\bar{p}=\tilde{\tilde{p}}$ with $\tilde{p}<\tilde{\tilde{p}} \leq \min \left\{p_{1,1}, \phi_{0}\left(p_{0,0}\right)\right\}$ is observed. This price is equilibrium dominated for a bank with $s_{b}=0$ by definition of $\phi_{0}\left(p_{0,0}\right)$. The low-signal bank can therefore be excluded from the set of potential deviators. The only remaining agent is the high-signal bank. The best response of high-signal investors then is to buy at $\bar{p}=\tilde{\tilde{p}}$ (i.e., $B_{1}$ ). Hence the PBE with $\overline{\mathrm{p}}^{*}=\tilde{p}$ does not survive the IC. Applying this reasoning repeatedly, all separating prices with $\overline{\mathrm{p}}<\min \left\{p_{1,1}, \phi_{0}\left(p_{0,0}\right)\right\}$ can be eliminated.

Step $2 a$ (Pooling with $B_{0,1}$ ). For all investors to buy, we must have $\mathrm{p} \leq p_{0,1 / 2}$. Suppose there was deviation to $\mathrm{p}=\phi_{1}\left(p_{0,1 / 2}\right)<\phi_{0}\left(p_{0,1 / 2}\right)$. For the low-signal bank, this would not be profitable by definition of $\phi_{0}\left(p_{0,1 / 2}\right)$. But for some beliefs about the signal of the bank and corresponding best responses, high-signal investors could be better off. The best response for investors with beliefs on the remaining set of types (i.e., $\mu=1$ ), however, is $B_{1}$, as we have $\phi_{1}\left(p_{0,1 / 2}\right)<p_{1,1}$. Hence, applying IC, there cannot be a pooling equilibrium with $B_{0,1}$.

Step $2 b$ (Pooling with $B_{1}$ ). We must have $\mathrm{p} \leq p_{1,1 / 2}$. Since $\phi_{0}\left(p_{0,0}\right)>p_{1,1 / 2}$, the low-signal bank would prefer to deviate to $p_{0,0}$, hence this cannot be an equilibrium.

To summarize, restrictions $\phi_{1}\left(p_{0,1 / 2}\right)<p_{1,1}$ and $\phi_{0}\left(p_{0,0}\right)>p_{1,1 / 2}$ ensure that the only equilibrium surviving the IC is the one depicted in Proposition 1.

Proof of Proposition 2. It suffices to show the result for the highest possible separating offer prices as it will then necessarily hold for lower separating prices. The market price will resemble the true value of the security by the law of large numbers (LLN) applied to informative signals. Assumptions 1 and 2 imply that the IPO fails with probability 0.5 if the bank sets the high separation price and the true value is $V=0$. Likewise, if the true value is $V=1$, then the IPO never fails. The bank sets the high price when it receives the high signal, and it sets the low price when it sets the low signal. If the true value is $V=1$ then there is underpricing of 1 -price. If the true value is $V=0$, then there is underpricing of - price. Using the signal probabilities, average underpricing is

$$
\begin{aligned}
\operatorname{Pr}(V & =1)\left[q_{b}\left(1-p_{1,1}\right)+\left(1-q_{b}\right)\left(1-p_{0,0}\right)\right] \\
& +\operatorname{Pr}(V=0)\left[\frac{1-q_{b}}{2} \cdot\left(-p_{1,1}\right)+q_{b}\left(-p_{0,0}\right)\right]= \\
& \frac{1}{2}\left[1-p_{0,0}-\frac{1+q_{b}}{2} p_{1,1}\right]=\frac{1}{2}\left(1-q_{b}-p_{0,0}\right),
\end{aligned}
$$


where the last step follows using the closed-form prices from Appendix C. Straightforward algebra yields that $1-q-p_{0,0}>0$ for all $q_{b}, q_{i}>1 / 2$.

Proof of Lemma 2. Without short covering, all profits stem from the gross spread; with short covering, there are also profits from short covering. Fixing all exogenous parameters, the offer revenue stays constant when short covering is introduced because the amount of floated securities is assumed to remain constant. It thus suffices to check if for a fixed price $\phi_{0}\left(p_{0,0}\right)$, short-covering profits for the low-signal bank are higher than for price $p_{0,0}$. For if so, then the high-signal bank has to lower the price to prevent a deviation by the low-signal bank.

The low-signal bank knows that the aftermarket price falls whenever demand is low. Employing the closed-form probabilities and prices that we derive in Appendix C, the lowsignal bank attaches probability $q_{b} / 2$ to the case that the IPO goes through at risky price $\phi_{0}\left(p_{0,0}\right)$ and that prices then fall in the aftermarket. By the LLN, short covering always occurs at price 0 . Rising prices are no concern because of the overallotment option. The total expected short-covering payoffs are thus $\Pi^{\mathrm{SC}}\left(\phi_{0}\left(p_{0,0}\right) \mid B_{1}, s_{b}=0\right)=(1-\beta) \mathrm{O} \phi_{0}\left(p_{0,0}\right) q_{b} / 2$. If the bank sets the low price, $p_{0,0}$, then the offer will always go through, and prices drop in the aftermarket with probability $q$. Expected payoffs are thus $\Pi^{\mathrm{SC}}\left(p_{0,0} \mid B_{0,1}, s_{b}=0\right)=$ $(1-\beta) \mathrm{O} p_{0,0} q_{b}$. Thus

$$
\Pi^{\mathrm{SC}}\left(\phi_{0}\left(p_{0,0}\right) \mid B_{1}, s_{b}=0\right)-\Pi^{\mathrm{SC}}\left(p_{0,0} \mid B_{0,1}, s_{b}=0\right)=(1-\beta) \mathrm{O} q_{b}\left[\phi_{0}\left(p_{0,0}\right) / 2-p_{0,0}\right] .
$$

Assumption 4 ensures that the above is positive because $\phi_{0}\left(p_{0,0}\right) / 2-p_{0,0}>p_{1,1 / 2} / 2-$ $p_{0,0}>0$.

Proof of Proposition 3. Lemma 2 ensures that $\underline{C}^{\mathrm{SC}} \geq \underline{C}$. The model is set up so that all payoffs $\Pi+\Pi^{\mathrm{SC}}$ can be dealt with as one. The pooling outcome transpires analogously to Proposition 1; payoff dominance rules out separating equilibria in which both types of banks make lower profits than in the pooling equilibrium. Value $\hat{C}^{\mathrm{SC}}$ exists analogously to Proposition 1, and Lemma 2 ensures that $\hat{C}^{\mathrm{SC}}>\hat{C}$. By definition, for $C>\hat{C}^{\mathrm{SC}}$, the highest attainable price is $p_{1,1}$, and it is the only one selected by IC.

Proof of Proposition 4. From Proposition 3 we know that a pooling equilibrium results for all $C<\underline{C}^{\mathrm{SC}}$. Value $\underline{C}^{\mathrm{SC}}$ is defined as the value of $C$ for which equation (11) is fulfilled with $\phi_{0}^{\mathrm{SC}}\left(p_{0,0}\right)=p_{1,1 / 2}$. Solving for $\underline{C}^{\mathrm{SC}}$ one obtains

$$
\underline{C}^{\mathrm{SC}}=\frac{\beta(\mathrm{S}+\mathrm{O})}{1-\alpha_{0}}\left(\alpha_{0} p_{1, \frac{1}{2}}-p_{0,0}\right)+\frac{(1-\beta) \mathrm{O} q_{b}}{1-\alpha_{0}}\left(\frac{p_{1, \frac{1}{2}}}{2}-p_{0,0}\right) .
$$

Partially differentiating with respect to $\mathrm{O}$ we obtain

$$
\frac{\partial \underline{C}^{\mathrm{SC}}}{\partial \mathrm{O}}=\frac{\beta}{1-\alpha_{0}}\left(\alpha_{0} p_{1, \frac{1}{2}}-p_{0,0}\right)+\frac{(1-\beta) q_{b}}{1-\alpha_{0}}\left(\frac{p_{1, \frac{1}{2}}}{2}-p_{0,0}\right) .
$$

Both terms in brackets are positive by Assumption 4 as long as $q_{b}<1$. Using that $\mathrm{S}+\mathrm{O}=$ $(1+r) \mathrm{S}$, partial differentiation with respect to $\beta$ yields

$$
\text { (B-3) } \begin{aligned}
\frac{\partial \underline{C}^{\mathrm{SC}}}{\partial \beta} & =\frac{\mathrm{S}(1+r)}{1-\alpha_{0}}\left(\alpha_{0} p_{1, \frac{1}{2}}-p_{0,0}\right)-\frac{r \mathrm{~S} q_{b}}{1-\alpha_{0}}\left(\frac{p_{1, \frac{1}{2}}}{2}-p_{0,0}\right) \\
& =\frac{\mathrm{S}}{1-\alpha_{0}}\left(\left((1+r) \alpha_{0}-r\left(1-\alpha_{0}\right)\right)\left(p_{1, \frac{1}{2}}-2 p_{0,0}\right)+p_{0,0}\left(2 \alpha_{0}-1\right)\right) .
\end{aligned}
$$

As $\alpha_{0}>1-\alpha_{0}$, all terms are positive. 
Exacerbated underpricing occurs for costs in the region $\left(\underline{C}^{\mathrm{SC}}, \hat{C}^{\mathrm{SC}}\right)$. We now show that $\hat{C}^{\mathrm{SC}}$ increases in $\beta$ and $\mathrm{O}$ and that it increases more than $\underline{C}^{\mathrm{SC}}$. This requires the same steps as above:

$$
\begin{aligned}
& \text { (B-4) } \quad \hat{C}^{\mathrm{SC}}=\frac{\beta(\mathrm{S}+\mathrm{O})}{1-\alpha_{0}}\left(\alpha_{0} p_{1,1}-p_{0,0}\right)+\frac{(1-\beta) \mathrm{O} q_{b}}{1-\alpha_{0}}\left(\frac{p_{1,1}}{2}-p_{0,0}\right) \text {, } \\
& \text { (B-5) } \frac{\partial \hat{C}^{\mathrm{SC}}}{\partial \mathrm{O}}=\frac{\beta}{1-\alpha_{0}}\left(\alpha_{0} p_{1,1}-p_{0,0}\right)+\frac{(1-\beta) q_{b}}{1-\alpha_{0}}\left(\frac{p_{1,1}}{2}-p_{0,0}\right)>0 \text {, } \\
& \text { (B-6) } \frac{\partial \hat{C}^{\mathrm{SC}}}{\partial \beta}=\frac{\mathrm{S}}{1-\alpha_{0}}\left(\left((1+r) \alpha_{0}-r\left(1-\alpha_{0}\right)\right)\left(p_{1,1}-2 p_{0,0}\right)+p_{0,0}\left(2 \alpha_{0}-1\right)\right) \\
& >0 \text {. }
\end{aligned}
$$

Obviously, $p_{1,1}>p_{1,1 / 2}$, so that the respective derivatives are all larger for $\hat{C}^{\mathrm{SC}}$ than for $\underline{C}^{\mathrm{SC}}$.

\section{Appendix C. Threshold Prices and Their Closed Forms}

Threshold Prices. Denote by $p_{s_{i}, \mu}$ the maximum price at which an investor with signal $s_{i}$ and price information $\mu$ buys, given all investors with $\tilde{s_{i}} \geq s_{i}$ buy. At this price the investor's expected return from buying the security is 0 , normalizing outside investment opportunities accordingly.

Define $\psi(1 \mid 1,1):=\operatorname{Pr}\left(V=1 \mid s_{i}=1, \mu=1\right)$ and $\psi(0 \mid 1,1):=\operatorname{Pr}\left(V=0 \mid s_{i}=1, \mu=1\right)$. Consider now the structure of the conditional distribution $f(d-1 \mid V)$. For $V=1$, this is a binomial distribution over $\{0, \ldots, N-1\}$ with center $(N-1) q_{i}$, and likewise for $V=0$ with center $(N-1)\left(1-q_{i}\right)$. Since by Assumption 2, $N$ is "large enough" for every $q_{i}, f(d-1 \mid 1)=0$ for $d<N / 2$ and $f(d-1 \mid 0)=0$ for $d \geq N / 2$. When combining $f(d-1 \mid 1)$ and $f(d-1 \mid 0)$, we obtain a bimodal function. In $g\left(d-1 \mid s_{i}, \mu\right)$, investors' posterior distribution over demands, these are weighted with $\psi\left(1 \mid s_{i}, \mu\right)$ and $\psi\left(0 \mid s_{i}, \mu\right)$. Assumption 2 now satisfies two purposes. The first is to ensure that we pick $N$ large enough so that the two humps do not overlap. The second can be seen from the following insight:

Claim. For $q_{i}>1 / 2$ and any $\delta>0$, there exist a number of investors $N\left(q_{i}\right)$, such that

$$
\sum \mathrm{p}^{m}(d) f(d-1 \mid 0)<\delta, \quad \text { and } \quad \sum \mathrm{p}^{m}(d) f(d-1 \mid 1)>1-\delta .
$$

The claim states that market prices are mostly 0 or 1 ; if they are not, then the weight of this demand is negligible. To see this, consider the following heuristic argument. Figure $\mathrm{C} 1$ provides an intuitive illustration of how the increase in $N$ yields the result.

Proof. Say $\mathrm{p}^{m}(d)$ as given by equation (A-2) is an S-shaped function in $d$ that is 0 below $N / 2$ and 1 above for almost all $d$ when $N$ is large. We focus on the lower tail, when $d<N / 2$; the case for $d \geq N / 2$ follows analogously. For fixed $\epsilon$, define $d^{*}$ as the threshold value that solves $\mathrm{p}^{m}(d)=\epsilon$ and increases linearly in $N$ (it is at constant distance from $N / 2$ ). Density $g\left(d-1 \mid s_{i}, \mu\right)$ peaks at $(N-1)\left(1-q_{i}\right)$ and $(N-1) q_{i}$. For large $N$, the two binomial distributions in $g$ are normal by DeMoivre-Laplace, and because the standard deviation is increasing in $N$ only by $\sqrt{N}$, the distributions become more concentrated around their means. Let $d^{* *}$ denote the demand so that the weight under $f(d-1 \mid 0)$ for values above $d^{* *}$ is smaller than $\epsilon, \sum_{d=d^{* *}}^{N} f(d-1 \mid 0)=\epsilon$. Then $d^{* *}$ increases in $N$ at rate $\approx \sqrt{N}$ (i.e., less than linear). This implies that there is a value $N^{*}$ so that $d^{*}>d^{* *}$. Consequently, $\sum \mathrm{p}^{m}(d) f(d-1 \mid 0)<(1-\epsilon) \cdot \epsilon+\epsilon \cdot 1=: \delta$ and can thus be made arbitrarily small. 


\title{
FIGURE C
}

\section{The Market Price and the Distribution of Favorable Signals in Dependence of the Number of Investors}

\begin{abstract}
Figure $\mathrm{C} 1$ illustrates how the shape of the aftermarket price function and the distribution of favorable signals change in the number of investors. Graphs A-C are plotted for $q_{i}=q_{b}=0.75$. The conditional probability distribution over $d-1$ others' favorable signals as described in Appendix $C$ is plotted from the perspective of an investor who has favorable information. The market price $p^{m}(d)$ is as in equation $(A-2)$, but it has been rescaled to simplify the visualization; it is the dashed line. Graph A plots the probability of $d-1$ favorable signals and the market price for $N=10$. The conditional signal distributions $f(d-1 \mid 0)$ and $f(d-1 \mid 1)$ are clearly not symmetric around their modes. For $N=50$, as in Graph B, the two distributions $f(d-1 \mid 0)$ and $f(d-1 \mid 1)$ are already almost symmetric around their modes and also the "overlap" with values in $p^{m}(d)$ that are not 0 or 1 is small. In Graph C, $N=100$ and this overlap is almost nonexistent.
\end{abstract}

Graph A. $N=10$

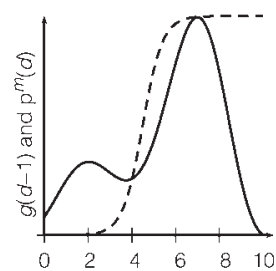

Graph B. $N=50$

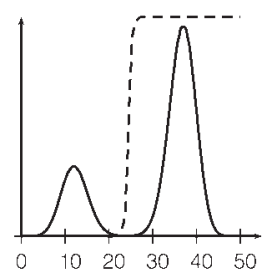

Graph C. $N=100$

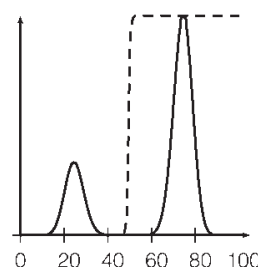

A simple application of this claim is that

$$
\begin{aligned}
& \sum_{d=N / 2}^{N} \mathrm{p}^{m}(d) \frac{\mathrm{S}}{d} g(d-1 \mid 1,1) \approx 1 \cdot \sum_{d=N / 2}^{N} \frac{\mathrm{S}}{d} g(d-1 \mid 1,1), \\
& \sum_{d=\mathrm{S}}^{N / 2-1} \mathrm{p}^{m}(d) \frac{\mathrm{S}}{d} g(d-1 \mid 1,1) \approx 0 .
\end{aligned}
$$

Using the claim, we can determine the threshold prices as follows: Consider first $p_{1,1}$.

$$
\begin{aligned}
0 & =\left(1-p_{1,1}\right) \sum_{d=N / 2}^{N} \frac{\mathrm{S}}{d} g(d-1 \mid 1,1)-p_{1,1} \sum_{d=\mathrm{S}}^{N / 2-1} \frac{\mathrm{S}}{d} g(d-1 \mid 1,1) \\
\Leftrightarrow \quad p_{1,1} & =\frac{\sum_{d=N / 2}^{N} \frac{\mathrm{S}}{d} g(d-1 \mid 1,1)}{\sum_{d=\mathrm{S}}^{N} \frac{\mathrm{S}}{d} g(d-1 \mid 1,1)} .
\end{aligned}
$$

For $d \geq N / 2, g\left(d-1 \mid s_{i}, \mu\right)=\psi\left(1 \mid s_{i}, \mu\right) f(d-1 \mid 1)$ and for $d<N / 2, g\left(d-1 \mid s_{i}, \mu\right)=$ $\psi\left(0 \mid s_{i}, \mu\right) f(d-1 \mid 0)$. Also define

$$
\begin{aligned}
\Sigma_{0}:=\sum_{d=\mathrm{S}}^{N / 2-1} f(d-1 \mid 0) / d \quad \text { and likewise } \\
\Sigma_{1}:=\sum_{d=N / 2}^{N} f(d-1 \mid 1) / d, \quad \text { and } \quad \sigma \quad:=\frac{\Sigma_{0}}{\Sigma_{1}} .
\end{aligned}
$$

Also write $\ell(\mu):=\psi(0 \mid 1, \mu) / \psi(1 \mid 1, \mu)$. Thus, for the combination of signal $s_{i}$ and priceinformation $\mu$ with $B_{1}$, we can write

$$
\text { (C-2) } p_{1,1}=(1+\sigma \ell(1))^{-1} \quad \text { and likewise } \quad p_{1, \frac{1}{2}}=\left(1+\sigma \ell\left(\frac{1}{2}\right)\right)^{-1} .
$$


Consider now the case for $p_{0,0}$. At this price all agents receive the security with equal probability and we sum from 1 to $N$. Thus

$$
\begin{aligned}
0 & =\left(1-p_{0,0}\right) \sum_{d=N / 2}^{N} \frac{\mathrm{S}}{N} g(d-1 \mid 0,0)-p_{0,0} \sum_{d=1}^{N / 2-1} \frac{\mathrm{S}}{N} g(d-1 \mid 0,0) \\
\Leftrightarrow \quad p_{0,0} & =\psi(1 \mid 0,0) .
\end{aligned}
$$

Likewise we have

$$
p_{0, \frac{1}{2}}=\psi\left(1 \mid 0, \frac{1}{2}\right) .
$$

Closed Forms of Threshold Prices. We will now derive approximate closed-form solutions so that we can solve our model analytically. In this Appendix we let $d$ denote the number of other investors with favorable information - this contrasts with the previous exposition but simplifies the notation here. First consider the strategy of agent number $N$. There are $N-1$ other investors. Given that he invests and the true value is, say, $V=1$, then by the LLN, demand/the number of favorable signals will always be larger than $N / 2$. Furthermore, the market price is almost surely $\mathrm{p}^{m}(d)=1$. If $d$ others order, then when buying he gets the asset with probability $1 /(d+1)$. Thus his payoff for price $\mathrm{p}$ is

$$
\begin{aligned}
& (1-\mathrm{p}) \sum_{d=\mathrm{S}-1}^{N-1} \frac{1}{d+1}\left(\begin{array}{c}
N-1 \\
d
\end{array}\right) q_{i}{ }^{d}\left(1-q_{i}\right)^{N-1-d} \\
& =(1-\mathrm{p}) \sum_{d=N / 2}^{N-1} \frac{1}{d+1}\left(\begin{array}{c}
N-1 \\
d
\end{array}\right) q_{i}{ }^{d}\left(1-q_{i}\right)^{N-1-d} .
\end{aligned}
$$

To compute the sum, we proceed in a similar manner as one would to compute the expected value of a binomial distribution. First observe that for large $N$ the following holds (approximately):

$$
\sum_{d=N / 2}^{N-1} \frac{1}{d+1}\left(\begin{array}{c}
N-1 \\
d
\end{array}\right) q_{i}{ }^{d}\left(1-q_{i}\right)^{N-1-d}=\sum_{d=0}^{N-1} \frac{1}{d+1}\left(\begin{array}{c}
N-1 \\
d
\end{array}\right) q_{i}{ }^{d}\left(1-q_{i}\right)^{N-1-d} .
$$

Then we can compute

$$
\begin{aligned}
& \sum_{d=0}^{N-1} \frac{1}{d+1}\left(\begin{array}{c}
N-1 \\
d
\end{array}\right) q_{i}{ }^{d}\left(1-q_{i}\right)^{N-1-d} \\
& \quad=\frac{1}{q_{i} N} \sum_{d=0}^{N-1} \frac{N !}{(N-(d+1)) !(d+1) !} q_{i}^{d+1}\left(1-q_{i}\right)^{N-1-d} \\
& =\frac{1}{q_{i} N}\left(\sum_{l=0}^{N}\left(\begin{array}{c}
N \\
l
\end{array}\right) q_{i}^{l}\left(1-q_{i}\right)^{N-l}-\left(\begin{array}{c}
N \\
0
\end{array}\right) q_{i}^{0}\left(1-q_{i}\right)^{N-0}\right) \\
& =\frac{1}{q_{i} N}\left(1-\left(1-q_{i}\right)^{N}\right) .
\end{aligned}
$$

In the second step we made a change of variable, $l=d+1$, but through this change we had to subtract the element of the sum for $l=0$. Consequently, for large $N$, we can say that

$$
\begin{aligned}
& \sum_{d=N / 2}^{N-1} \frac{1}{d+1}\left(\begin{array}{c}
N-1 \\
d
\end{array}\right) q_{i}{ }^{d}\left(1-q_{i}\right)^{N-1-d} \approx \frac{1}{q_{i} N} \text { and } \\
& \sum_{d=0}^{N-1} \frac{1}{d+1}\left(\begin{array}{c}
N-1 \\
d
\end{array}\right) q_{i}^{N-1-d}\left(1-q_{i}\right)^{d} \approx \frac{1}{\left(1-q_{i}\right) N} .
\end{aligned}
$$


Recall that we can write $p_{1,1}$ as

$$
p_{1,1}=\frac{1}{1+\ell(1) \frac{\Sigma_{0}}{\Sigma_{1}}} .
$$

We now need to find a closed form for

$$
\Sigma_{0}=\sum_{d=\mathrm{S}-1}^{N / 2} \frac{1}{d+1}\left(\begin{array}{c}
N-1 \\
d
\end{array}\right) q_{i}^{N-1-d}\left(1-q_{i}\right)^{d} .
$$

For increasing $N$ one can see that $(1 /(d+1))\left(\begin{array}{c}N-1 \\ d\end{array}\right) q_{i}^{N-1-d}\left(1-q_{i}\right)^{d}$ gets numerically symmetric around $\left(1-q_{i}\right)(N-1)$. Thus we can express

$$
\begin{aligned}
\Sigma_{0} & =\frac{1}{2} \sum_{d=0}^{N / 2} \frac{1}{d+1}\left(\begin{array}{c}
N-1 \\
d
\end{array}\right) q_{i}^{N-1-d}\left(1-q_{i}\right)^{d} \\
& =\frac{1}{2} \sum_{d=0}^{N} \frac{1}{d+1}\left(\begin{array}{c}
N-1 \\
d
\end{array}\right) q_{i}^{N-1-d}\left(1-q_{i}\right)^{d} \\
& \approx \frac{1}{2} \frac{1}{\left(1-q_{i}\right) N} .
\end{aligned}
$$

Combining terms, we obtain

$$
\begin{aligned}
p_{1,1} & =\frac{1}{1+\ell(1) \frac{\Sigma_{0}}{\Sigma_{1}}} \approx \frac{1}{1+\frac{\left(1-q_{i}\right)\left(1-q_{b}\right)}{q_{i} q_{b}} \frac{q_{i} N}{2\left(1-q_{i}\right) N}} \\
& =\frac{2 q_{b}}{1+q_{b}} \equiv \frac{q_{b}}{\alpha_{1}} .
\end{aligned}
$$

Similarly, we get

$$
\text { (C-11) } p_{1, \frac{1}{2}} \approx \frac{1}{1+\frac{1-q_{i}}{q_{i}} \frac{q_{i} N}{2\left(1-q_{i}\right) N}}=\frac{2}{3}, \quad \text { and } \quad p_{0,1} \quad \approx \quad \frac{1-q_{b}}{\alpha_{0}} \text {. }
$$

The information content of a high pooling price is $1 / 2$, and knowing this information, the probability of the offering being successful is $3 / 4$. Thus the interpretation of risky prices is the ratio of the expected liquidation value given price information to the share of successful offerings given this information:

$$
p_{1, \mu}=\frac{\mathrm{E}[V \mid \mu]}{\operatorname{Pr}(\mathrm{IPO} \text { successful } \mid \mu)} .
$$

\section{Appendix D. Maximal Reputation Costs}

If an IPO fails, the worst that can happen is that the investment bank loses all future IPO business (i.e., it is out of the market). Assuming that future business takes place in the same environment (e.g., the quality of signals remains constant), the bank can maximally lose all discounted future profits. Assume that the bank discounts future profits at rate $\delta$. Consider the case of highest potential costs $\bar{C}$ that can occur from a failing IPO in a 
separating equilibrium. An upper bound for costs is given by the discounted lost future profits if $\overline{\mathrm{p}}=p_{1,1}$. Then ex ante profits of a single IPO are

$$
\Pi\left(p_{0,0}, p_{1,1}, C\right)=\frac{1}{2}(\mathrm{~S}+\mathrm{O}) \beta\left(p_{0,0}+\frac{1+q_{b}}{2} p_{1,1}\right)-\frac{1-q_{b}}{4} C .
$$

Assuming that an investment bank would conduct one IPO each period and accounting for the fact that in a separating equilibrium the ex ante probability of the IPO to be successful is $\left(3+q_{b}\right) / 4$, we get

$$
C_{\max }=\sum_{t=0}^{\infty}(1-\delta)^{t} \cdot\left(\left(3+q_{b}\right) / 4\right)^{t} \cdot \Pi\left(p_{0,0}, p_{1,1}, C_{\max }\right) .
$$

Solving for maximal possible costs, we obtain

$$
C_{\max }=2(\mathrm{~S}+\mathrm{O}) \beta \frac{p_{0,0}+\frac{1+q_{b}}{2} p_{1,1}}{\delta\left(3+q_{b}\right)+2\left(1-q_{b}\right)} .
$$

Comparing values of $C_{\max }$ to those of $\bar{C}$ shows that for $q_{i}$ and $q_{b}$ sufficiently large $\bar{C} \gg$ $C_{\max }$. Furthermore, for reasonable values of the discount rate, the reverse relation holds true only for values of $q_{i}$ and $q_{b}$ where we get $\bar{C}^{\text {SC }}<\bar{C}$. That is, either $\bar{C}^{\text {SC }}<\bar{C}$ and informational inefficiencies result, or $\bar{C}$ is so large that it lies outside the relevant parameter region in the context of this model.

\section{Appendix E. Payoff Comparison}

To compare payoffs, we compute these both when short covering is allowed and when it is not. In the computations, we employ the closed-form price and probability approximations derived above. When computing payoffs numerically, we use the empirically observed numbers $\beta=7 \%$ and $\mathrm{O}=15 \% \mathrm{~S}$.

Payoffs for High- and Low-Signal Banks Combined. First observe that if costs are lower than $\underline{C}$ or if costs are higher than $\hat{C}^{\mathrm{SC}}$, then banks always win. The reason is that in both cases the prices and thus expected revenues remain constant. In addition, the bank earns short-covering profits.

We consider two special cases.

First, suppose that costs are exactly $\hat{C}$. We then know that without short covering, the high price is $p_{1,1}$. Let us focus on the case where at this cost with short covering, banks pool in price $p_{1,1 / 2}$. We know that $\hat{C}$ is defined so that

$$
\Pi\left(p_{0,0} \mid s_{b}=0, B_{0,1}\right) \quad=\quad \Pi\left(p_{1,1} \mid s_{b}=0, B_{1}\right) .
$$

We can therefore express these profits as

$$
\begin{aligned}
& \Pi\left(p_{0,0} \mid s_{b}=0, B_{0,1}\right)+\Pi\left(p_{1,1} \mid s_{b}=1, B_{1}\right)= \\
& \quad\left(\alpha_{1}+\alpha_{0}\right) \beta \mathrm{S}(1+r) p_{1,1}-\left(\left(1-\alpha_{1}\right)+\left(1-\alpha_{0}\right)\right) C .
\end{aligned}
$$

With short covering, profits are

$$
\begin{aligned}
\Pi\left(p_{1, \frac{1}{2}} \mid s_{b}=0, B_{1}\right)+\Pi\left(p_{1, \frac{1}{2}} \mid s_{b}=1, B_{1}\right)+\Pi^{\mathrm{SC}}\left(p_{1, \frac{1}{2}} \mid s_{b}=0, B_{1}\right)+\Pi^{\mathrm{SC}}\left(p_{1, \frac{1}{2}} \mid s_{b}=1, B_{1}\right) \\
=\quad\left(\alpha_{1}+\alpha_{0}\right) \beta \mathrm{S}(1+r) p_{1, \frac{1}{2}}-\left(\left(1-\alpha_{1}\right)+\left(1-\alpha_{0}\right)\right) C \\
\quad+\left(\left(1-\alpha_{1}\right)+\left(1-\alpha_{0}\right)\right)(1-\beta) p_{1, \frac{1}{2}} r \mathrm{~S} .
\end{aligned}
$$


Substituting for the closed-form approximations of prices and probabilities, and then taking the difference of payoffs with and without short covering, this simplifies to

$$
\mathrm{S}\left(\beta(1+r)\left(1-\frac{3 q_{b}}{1+q_{b}}\right)+\frac{1}{3}(1-\beta) r\right) .
$$

This is positive as long as $r$ is sufficiently larger than $\beta$ and holds, for instance, for the empirically observed values $r=15 \%, \beta=7 \%$. For this reason, the gray line is always above the black line at $\hat{C}$ in Graph B of Figure 4 .

The second scenario that we study is when costs are $\underline{C}^{\mathrm{SC}}$. In this case, $\phi_{0}^{\mathrm{SC}}\left(p_{0,0}\right)=$ $p_{1,1 / 2}$. The most extreme drop in revenue happens when $\hat{C}<\underline{C}^{\mathrm{SC}}$, so that without short covering at the costs that we consider, the bank plays a separation equilibrium with high price $p_{1,1}$. Note that for such a cost $\underline{C}^{\text {SC }}>\hat{C}$, without short covering the low-signal bank is not indifferent between a risky and a riskless price as $\phi_{0}\left(p_{0,0}\right)>p_{1,1}$ and thus strictly prefers the low separation price. With short covering, by the definition of $\underline{C}^{\mathrm{SC}}$, the lowsignal bank is indifferent between the risky price $p_{1,1 / 2}$ and the risk-free low separation price $p_{0,0}$. So the differences to the above computations are the payoffs for the low-signal type,

$$
\Pi_{1}\left(p_{0,0} \mid s_{b}=0, B_{0,1}\right) \quad=\quad p_{0,0} \beta \mathrm{S}(1+r),
$$

$(\mathrm{E}-5) \Pi_{1}\left(p_{0,0} \mid s_{b}=0, B_{0,1}\right)+\Pi_{2}\left(p_{0,0} \mid s_{b}=0, B_{0,1}\right) \quad=\quad p_{0,0} \beta \mathrm{S}(1+r)+q(1-\beta) r \mathrm{~S} p_{0,0}$.

Combining this with the high-signal bank's payoff and taking differences, we find that if

$$
\left((1-q)(1-\beta) r-(2 q-1) \beta(1+r)+3 q(1-\beta) p_{0,0}\right) \mathrm{S} / 3<0
$$

then the bank loses on average. The upper right segment in Graph A of Figure 4 represents the parameter configurations $q_{b}$ and $q_{i}$ where this occurs.

With respect to signal qualities, this area appears to be significant. But note that this is the most extreme case in all dimensions: This scenario arises only for the special case that also $\underline{C}^{S C}>\hat{C}$, and it only arises in a strict subinterval of $\left[\hat{C}, \hat{C}^{S C}\right]$. Moreover, even in the special case, the bank is on average better off for all other costs. Graph B of Figure 4 illustrates this point. To summarize, the bank is almost always better off, on average.

\section{References}

Aggarwal, R. "Stabilization Activities by Underwriters after Initial Public Offerings." Journal of Finance, 55 (2000), 1075-1103.

Benveniste, L. M.; W. Busaba; and W. J. Wilhelm. "Price Stabilization as a Bonding Mechanism in Equity Issues." Journal of Financial Economics, 42 (1996), 223-255.

Benveniste, L. M., and P. A. Spindt. "How Investment Bankers Determine the Offer Price and Allocation of New Issues." Journal of Financial Economics, 24 (1989), 343-361.

Benveniste, L. M., and W. J. Wilhelm. "A Comparative Analysis of IPO Proceeds under Alternative Regulatory Environments." Journal of Financial Economics, 28 (1990), 173-207.

Boehmer, E., and R. Fishe. "Underwriter Short Covering in the IPO Aftermarket: A Clinical Study." Journal of Corporate Finance, 10 (2004), 575-594.

Busaba, W. Y. "Bookbuilding, the Option to Withdraw, and the Timing of IPOs." Journal of Corporate Finance, 12 (2006), 159-186.

Chen, H.-C., and J. R. Ritter. "The Seven Percent Solution.” Journal of Finance, 55 (2000), 11051131.

Chen, Z., and W. J. Wilhelm. "A Theory of the Transition to Secondary Market Trading of IPOs." Journal of Financial Economics, 90 (2008), 219-236.

Cho, I.-K., and D. M. Kreps. "Signaling Games and Stable Equilibria." Quarterly Journal of Economics, 102 (1987), 179-221.

Chowdhry, B., and V. Nanda. "Stabilization, Syndication, and Pricing of IPOs." Journal of Financial and Quantitative Analysis, 31 (1996), 25-42.

Dunbar, C. G. "Factors Affecting Investment Bank Initial Public Offering Market Share." Journal of Financial Economics, 55 (2000), 3-41. 
Dunbar, C. G., and S. R. Foerster. "Second Time Lucky? Withdrawn IPOs that Return to the Market." Journal of Financial Economics, 87 (2008), 610-635.

Edwards, A. K., and K. W. Hanley. "Short Selling in Initial Public Offerings." Journal of Financial Economics, forthcoming (2010).

Ellis, K.; R. Michaely; and M. O'Hara. "When the Underwriter Is the Market Maker: An Examination of Trading in the IPO Aftermarket.” Journal of Finance, 55 (2000), 1039-1074.

Ellul, A., and M. Pagano. "IPO Underpricing and Aftermarket Liquidity." Review of Financial Studies, 19 (2006), 381-421.

Fishe, R. P. "How Stock Flippers Affect IPO Pricing and Stabilization." Journal of Financial and Quantitative Analysis, 37 (2002), 319-340.

Griffin, J. M.; J. H. Harris; and S. Topaloglu. "Why Are IPO Investors Net Buyers through Lead Underwriters?" Journal of Financial Economics, 85 (2007), 518-551.

Jenkinson, T., and A. Ljungqvist. Going Public: The Theory and Evidence on How Companies Raise Equity Finance, 2nd ed. Oxford and New York, NY: Oxford University Press (2001).

Jenkinson, T.; A. D. Morrison; and W. J. Wilhelm. "Why Are European IPOs So Rarely Priced Outside the Indicative Price Range?" Journal of Financial Economics, 80 (2006), 185-209.

Leland, H. E., and D. H. Pyle. "Informational Asymmetries, Financial Structure, and Financial Intermediation." Journal of Finance, 32 (1977), 371-387.

Rock, K. "Why New Issues Are Underpriced." Journal of Financial Economics, 15 (1986), 187-212.

SEC. "Regulation M." Release No. 34-38067, Securities and Exchange Commission (1997).

Zhang, D. "Why Do IPO Underwriters Allocate Extra Shares When They Expect to Buy Them Back?" Journal of Financial and Quantitative Analysis, 39 (2004), 571-594. 